\title{
Must-Take Cards: Merchant Discounts and Avoided Costs*
}

\author{
Jean-Charles Rochet ${ }^{\dagger} \quad$ and Jean Tirole ${ }^{\dagger}$
}

November 7, 2008

\begin{abstract}
Antitrust authorities often argue that merchants cannot reasonably turn down payment cards and therefore must accept excessively high merchant discounts. The paper attempts to shed light on this "must-take cards" view from two angles.

First, the paper gives some operational content to the notion of "must-take card" through the "avoided-cost test" or "tourist test": would the merchant want to refuse a card payment when a non-repeat customer with enough cash in her pocket is about to pay at the cash register? It analyzes its relevance as an indicator of excessive interchange fees.

Second, it identifies four key sources of potential social biases in the payment card systems' determination of interchange fees: internalization by merchants of a fraction of cardholder surplus, issuers' per-transaction markup, merchant heterogeneity, and extent of cardholder multi-homing. It compares the industry and social optima both in the short term (fixed number of issuers) and the long term (in which issuer offerings and entry respond to profitability).
\end{abstract}

Keywords: Card payment systems, interchange fee, internalization, multi-homing, avoided cost, tourist test.

${ }^{*}$ We are grateful to participants at seminars at Bocconi University, Dutch National Bank, Mannheim University, the OECD workshop on payment systems (June 6th 2006), the IDEI conference on competition policy in two-sided markets, and to Patrick Bolton, Luis Cabral, and especially Marius Schwartz and two anonymous referees for useful comments. The research leading to these results has received funding from the European Research Council under the European Community?s Seventh Framework Programme (FP7/2007-2013) Grant Agreement no. 249429.

†Toulouse School of Economics. 


\section{Introduction}

In payment cards systems such as Visa or MasterCard, the interchange fee (IF) paid by the merchant's bank (the "acquirer") to the cardholder's bank (the "issuer") allocates the total cost of the payment service between the two users, cardholder and merchant. In several regions of the world, competition authorities, banking regulators, and courts of justice have recently considered, or even implemented, regulatory caps on interchange fees that are based on issuers' costs. The premise for these regulatory caps is that unregulated IFs are set at unacceptably high levels. Merchants, the argument goes, accept to pay the resulting high merchant discount because they are concerned that turning down cards would impair their ability to attract customers; that is, cards are "must-take cards" (Vickers 2005). ${ }^{1}$

However, there is no logical connection between this "must-take cards" argument and the issuers' cost benchmark used by regulators. The main objectives of this paper are to analyze the validity of the argument and to derive policy implications for possible regulatory intervention. To this purpose, the paper develops a model of the payment card industry that is sufficiently rich to account for the complex effects of IFs on volumes of card payments, banks' profits, consumer welfare, and retail profits and prices, yet simple enough to assess their regulation.

First, the paper validates the "must-take cards" argument by showing that retailers may be willing to accept cards even if the fee they have to pay exceeds their convenience benefit for card payments. This is because accepting cards increases the retailer's quality of service by offering to his customers an additional payment option. This property holds whether retailers are perfect competitors, Hotelling-Lerner-Salop competitors or even local monopolists. Thus it is not due to an hypothetical "prisonner's dilemma" situation where

\footnotetext{
${ }^{1}$ In the UK, the Office of Fair Trading, following a multi-year investigation of MasterCard's credit card IFs, ruled that the multilateral setting of these IFs was anti-competitive. Similarly, under the pressure of the European Commission, Visa International agreed in 2002 to reduce its cross-border interchange fees on credit and debit transactions within the European Union. In its recent MasterCard decision (December 2007), the Commission went further and ruled that MasterCard IFs should be set to zero ("at par settlement"). In Australia, after the publication of an extensive study of debit and credit card schemes in 2000, the Reserve Bank of Australia mandated in 2003 a sizeable reduction of credit-card IFs. Other countries where similar decisions have been made (or are seriously considered) by courts of justice, competition authorities or banking regulators include Israel, Spain, Portugal, Belgium, and the Netherlands. The regulation of IFs may operate less directly, as was the case in the 2003 WalMart settlement in which MasterCard and Visa agreed to pay $\$ 3$ billion to merchants and to stop tying their credit and off-line debit cards (the merchants in particular complained that the IF on off-line debit was too high).
} 
retailers would accept cards only to steal business from each other.

Second, the paper provides an alternative benchmark for regulatory intervention. This benchmark is not based on issuers' costs, but on the retailer's avoided-cost when a cash (or check) payment is replaced by a card payment. The empirical counterpart of this benchmark, which we call the "tourist-test", gives some operational content to the notion of "must-take card": would the merchant want to refuse a card payment when a nonrepeat customer with enough cash in her pocket is about to pay at the cash register? Put differently, the merchant discount passes the tourist test if and only if accepting the card does not increase the merchant's operating costs. The paper analyzes the test's relevance as an indicator of excessive interchange fees. We show that, when issuers' margin are constant, the tourist test is an exact test of excessive interchange fees from the point of view of short-term consumer surplus, and yields false positives if the criterion is social welfare.

Third, the paper identifies four key sources of potential social biases in the payment card associations' determination of interchange fees: internalization by merchants of cardholder surplus, issuers' per-transaction markup, merchant heterogeneity, and extent of cardholder multi-homing. It compares the industry and social optima both in the short term (fixed number of issuers) and the long term (in which issuer offerings and issuer entry respond to profitability).

The paper is organized as follows: Section 2 assesses the impact of the pricing of payment cards services on card acceptance decisions by merchants and card usage decisions by consumers. It also introduces the avoided-cost benchmark and its empirical counterpart, the tourist test. Section 3 investigates whether the interchange fees maximizing short-term welfare and total user surplus (the latter equal to the former minus banks' profits), respectively, meet the tourist test. Section 4 compares privately and socially optimal interchange fees, first in the case of a monopoly platform, then when several platforms compete. Section 5 performs the same exercise as Section 3 in the long term, in which issuer entry and offerings respond to industry profitability (and so welfare and total user surplus coincide). Section 6 shows that retailer heterogeneity makes the tourist test more likely to produce false positives. Section 7 concludes.

Relation to the literature. The paper borrows from and extends a number of contributions to the literatures on card payments and two-sided markets. It elaborates on previous theoretical analyses (surveyed in Rochet (2003)) of the impact of IFs, in particular Rochet and Tirole (2002), Schmalensee (2002), and Wright (2003a, 2003b, 2004). In particular, 
the idea that merchants may accept cost-increasing means of payment is drawn from our earlier paper on card payments. Our analysis of merchant heterogeneity borrows from Schmalensee (2002) and Wright (2004). Wright built on Schmalensee and showed how the privately and socially optimal IFs depend on the elasticities on the two sides (merchants, cardholders). He argued that there is no systematic bias between the IF chosen by the association and the socially optimal IF. We also borrow from Wright the modelling of cardholder demand, which is a bit simpler than our initial modelling: Wright assumed that cardholders' convenience benefit is drawn at the moment of purchase while we presumed that cardholders differ systematically in the benefit that they derive from card payments. While ex post (Wright) and ex ante (Rochet-Tirole) heterogeneity deliver broadly convergent results, ex ante heterogeneity makes merchants' card acceptance decisions strategic complements rather than independent.

Finally, there is also a sizeable, less formal literature (surveyed in Schmalensee (2003)) on the potential anticompetitive effects of IFs, in particular Carlton and Frankel (1995), Evans and Schmalensee (1995), Frankel (1998), Chang and Evans (2000) and Balto $(2000) .^{2}$

While these contributions have substantially influenced this paper, none emphasizes the distinctions between the relevant measures of welfare (social welfare, total user surplus, consumer surplus) and their horizon (short vs. long term) and relates them to the tourist test, as we do. To the best of our knowledge, the literature has left largely unexplored the role of issuer, acquirer and merchant margins (Section 3) and of entry into credit card services (Section 5), and the link between the average merchant benefit and efficient IFs (Section 6).

\section{The model}

\section{$2.1 \quad$ Must-take cards}

There is a continuum of consumers (of total mass normalized to one) with quasi-linear preferences. They spend their income on a composite good or "cash good" taken as a numeraire and on one unit of a "card good" sold by $R$ retailers (being a "card good" means that consumers can pay by card as long as merchants accept it. "Cash goods" include

\footnotetext{
${ }^{2}$ This literature also addresses important questions that are left aside in the present paper: the impact of bans on merchant surcharges for cards, the redistributive issues involved in the subsidization of card usage by cash users, and the governance of card networks.
} 
leisure/work). The utility from purchasing the card good can differ across consumers, but is large enough, so that the aggregate demand for the card good is constant and equal to one. ${ }^{3}$ The unit cost of the card good for retailers is constant: it is denoted $\gamma$.

Consumers must decide which store to patronize. They know the stores' price and card acceptance policy before making this choice. Once in the store they must further select a payment method (a card or an alternative payment method, say cash), provided that the retailer indeed offers a choice among payment means. The benchmark model has a single card payment system. We assume "price coherence"; that is, the retailers either find it too costly or are not allowed to charge different prices for transactions settled by card and by cash. Whenever a transaction between a consumer (buyer) and a retailer (seller) is settled by card, the buyer pays transaction fee $p_{B}$ to his issuer and the seller pays merchant discount $p_{S}$ to her acquirer. We allow $p_{B}$ to be negative, in which case the cardholder receives a payment from his bank, in the form of interest-free period, cash back bonuses or air miles awarded to the buyer every time he uses his card. There are no annual fees and all consumers have a card.

The consumer's convenience cost of paying by cash (also the convenience benefit of using a card) is a random variable $\widetilde{b}_{B}$ drawn from cumulative distribution function $H$ :

$$
H\left(b_{B}\right)=\operatorname{Pr}\left(\widetilde{b}_{B} \leq b_{B}\right),
$$

We adopt the convention that the convenience cost for the buyer of a card payment is 0 . The distribution of $\tilde{b}_{B}$ has density $h\left(b_{B}\right)=H^{\prime}\left(b_{B}\right)$ and a monotone hazard rate: $\frac{h\left(b_{B}\right)}{1-H\left(b_{B}\right)}$ is increasing. We assume that the consumer only observes the realization of $\tilde{b}_{B}$ once in the store. Because the net benefit of paying by card is equal to the difference $\widetilde{b}_{B}-p_{B}$, a card payment is optimal for the consumer whenever $\widetilde{b}_{B} \geq p_{B}$. The proportion of card payments at a store that takes cards is denoted $D_{B}\left(p_{B}\right)$ :

$$
D_{B}\left(p_{B}\right)=\operatorname{Pr}\left(\widetilde{b}_{B} \geq p_{B}\right)=1-H\left(p_{B}\right) .
$$

$v_{B}\left(p_{B}\right)$ denotes the average net cardholder benefit per card payment:

$$
\begin{aligned}
v_{B}\left(p_{B}\right) & \equiv E\left[b_{B}-p_{B} \mid b_{B} \geq p_{B}\right] \\
& =\frac{\int_{p_{B}}^{\infty}\left(b_{B}-p_{B}\right) d H\left(b_{B}\right)}{\int_{p_{B}}^{\infty} d H\left(b_{B}\right)}>0 .
\end{aligned}
$$

\footnotetext{
${ }^{3}$ The analysis of the variant where the demand for the card good is elastic is provided in Appendix 6 .
} 
From the monotone hazard rate property, $v_{B}$ is a decreasing function ${ }^{4}$ of $p_{B}$.

The merchant's convenience benefit, $b_{S}$, is assumed to be homogeneous in a first step. We adopt a convention similar to that for cardholders: $b_{S}$ is the retailer's cost of a cash payment, while that for a card payment is normalized at 0 .

In order to illustrate the "must-take cards" idea, we posit that retailers' perceived benefit of accepting the card is equal to the sum of their convenience benefit and of the surplus the card brings to buyers:

Assumption 1. Retailers accept the card if and only if:

$$
p_{S} \leq b_{S}+v_{B}\left(p_{B}\right)
$$

Interestingly, this assumption is satisfied in three important cases:

Proposition 1. Assumption 1 is satisfied under monopoly retailing, under perfect retail competition, and under Hotelling-Lerner-Salop differentiated products competition.

Proof of Proposition 1: Monopoly retailer: Because retail demand is inelastic, the retail monopolist leaves no surplus to consumers. Accepting cards increases her per transaction cost by $\left(p_{S}-b_{S}\right)$ but allows her to increase her price by $v_{B}\left(p_{B}\right)$. Thus a retail monopolist accept cards if and only if $p_{S} \leq b_{S}+v_{B}\left(p_{B}\right)$.

Perfectly competitive retailer: Perfectly competitive retailers charge a retail price equal to their marginal cost, namely $p=\gamma$ (the cost of the good) if they reject cards, and $p=\gamma+\left(p_{S}-b_{S}\right) D_{B}\left(p_{B}\right)$ if they accept them. Consumers choose the retailers who accept cards if and only if their increased convenience benefit $v_{B}\left(p_{B}\right) D_{B}\left(p_{B}\right)$ exceeds the price increase $\left(p_{S}-b_{S}\right) D_{B}\left(p_{B}\right)$. Thus the only active retailers are the ones who accept cards if $p_{S} \leq b_{S}+v_{B}\left(p_{B}\right)^{5}$ and the ones who reject card if $p_{S}>b_{S}+v_{B}\left(p_{B}\right)$.

Hotelling-Lerner-Salop competition: Appendix 1 shows that retailers' card acceptance is also characterized by (3) in the (unique equilibrium of the) classic Hotelling-Lerner-Salop model of retailing.

Partial internalization: Appendix 1 also considers a more general case where consumers are informed about retailers' card acceptance only with probability $\alpha$, in which case cards

\footnotetext{
${ }^{4}$ This is a consequence of a well-known property of log-concave distribution functions (see Prékopa 1973).

${ }^{5}$ We assume that consumers pay by card also when $p_{S}=b_{S}+v_{B}\left(p_{B}\right)$.
} 
are accepted if and only if: 6

$$
p_{S} \leq b_{S}+\alpha v_{B}\left(p_{B}\right) \text {. }
$$

To understand formula (4), note that when consumers are unaware of the retailer's card acceptance policy, accepting the card does not help the retailer attract customers. And so the retailer accepts the card if and only if this reduces his operating cost: $p_{S} \leq$ $b_{S}$. When consumers know that the card is accepted $(\alpha=1)$, they expect to enjoy extra surplus $v_{B}\left(p_{B}\right)$ per card payment (recall that they do not know their convenience benefit before going to the store), and so the retailer can increase the retail price by the amount $v_{B}\left(p_{B}\right) D_{B}\left(p_{B}\right)$ while keeping sales constant. This price increase must exceed the operating cost increase in order for the retailer to accept the card.

Formula (4) reflects the idea that retailers internalize some of the cardholders' usage surplus and are therefore willing to accept cards even if their net cost of card transactions is positive (i.e., $p_{S}>b_{S}$ ). They are willing to incur a cost $p_{S}-b_{S}$ (provided that it is not too large) per card transaction, in order to offer a better quality of service to their customers (who value the option of paying by card). The parameter $\alpha$ measures the extent to which card acceptance makes their store more attractive to the consumer.

For the sake of simplicity and as stated earlier, we assume in the core of the paper that $\alpha=1$. Condition (3) then characterizes card acceptance by retailers.

\subsection{The avoided-cost or tourist test}

Retailers often complain that they are "forced" to accept card transactions that increase their net costs. To understand this "must-take cards" argument, one must distinguish between ex post and ex ante considerations. Once the customer has decided to buy from the retailer, it is in the latter's interest to "steer" the former to pay by cash or check instead of by card whenever $p_{S}>b_{S}$. But from an ex ante point of view, the retailer must also take into account the increase in store attractiveness brought about by the option of paying by card. Because retailers ex ante can always turn down cards, the "must-take cards" argument refers to the ex post perspective.

Let us accordingly introduce the "avoided-cost test" or "tourist test": suppose the buyer in question is a tourist, who will never patronize the store again in the future and shows up at the cash register with ostensibly enough cash to pay the wares. The merchant

\footnotetext{
${ }^{6}$ Again, this internalization of consumer surplus is unrelated to the extent of competition among retailers. Indeed, formula (4) applies to perfectly competitive retailers, to a retail monopolist and to Hotelling-Lerner-Salop competition.
} 
discount passes the tourist test if the retailer is willing to allow this consumer to pay by card, or equivalently if accepting the card does not increase the retailer's operating costs: $p_{S} \leq b_{S}$.

Definition: The merchant discount $p_{S}$ passes the tourist test if and only if accepting the card does not increase the retailer's net operating cost: $p_{S} \leq b_{S}$.

The attraction of the tourist test resides in the fact that the merchant pays no more than his convenience benefit from card payments. ${ }^{7}$ Capping the merchant discount at the merchant's convenience benefit prevents card payment systems from exploiting the internalization effect to force merchants to accept card payments that they do not want. Perhaps more importantly from an economic point of view, the absence of overpayment by the merchant suggests that the cardholder is not over-incentivized to use the card.

Whether the cap implied by the tourist test is reasonable, though, depends on whether cardholders are provided with the proper social incentive: The social optimum is reached only when the cardholders make the efficient decision with regards to the choice of payment method. As is usual, a "first-best rule" may no longer be adequate when the rest of the economy is already distorted. Potential distortions come from two sources:

(i) cardholders' incentives are already distorted: If merchants' fee equals their convenience benefit, the cardholder pays more than the net social cost of the card transaction (equal to the total cost of card payments, $c_{B}+c_{S}$, minus the merchant's benefit, $\left.b_{S}\right)$ whenever issuers (or acquirers for that matter) levy markups above cost. This suggests that cardholders may underconsume card payments if the merchant discount passes the tourist test.

(ii) merchants are heterogenous: When merchants differ in their convenience benefit $\left(b_{S}\right)$, inframarginal merchants derive more benefit from card payments than marginal ones. The tourist test can be applied to each merchant (or at least to merchants who end up accepting the card), but cardholders, whose usage fee does not depend on the merchant's identity, cannot be induced to exactly internalize the welfare of each merchant.

\footnotetext{
${ }^{7}$ Note that in the homogenous merchant model, the tourist test either holds or fails for all merchants. By contrast, in the heterogenous merchant model considered in Section 6, for some merchants may fail the tourist test while others pass it.
} 


\section{Socially optimal interchange fees}

We now model the payment card industry and investigate the impact of interchange fees on prices $p_{B}$ and $p_{S}$, and ultimately on social welfare and consumer surplus. Recall that, in a payment card association, the interchange fee (IF) $a$ represents the amount paid ${ }^{8}$ by the seller's bank (the acquirer) to the buyer's bank (the issuer) for each card transaction. It reallocates the total $\operatorname{cost}^{9} c=c_{B}+c_{S}$ of processing the transaction between the two banks. The acquirers' net marginal cost becomes $c_{S}+a$ and the issuers' becomes $c_{I} \equiv c_{B}-a$. We simplify the presentation by assuming that acquirers are perfectly competitive (we later note that the analysis generalizes in the presence of acquirer markups):

$$
p_{S}=c_{S}+a
$$

By contrast, issuers may have (ex post) market power. Subsection 3.1 presents the benchmark model where issuers' margin $m$ is constant. Subsection 3.2 considers the more general case of variable issuers' margin.

\subsection{Constant issuers' margin}

We start with the case where issuers' margin $m$ is constant:

$$
p_{B}=c_{I}+m=c_{B}-a+m .
$$

The interchange fee $a$ passes the tourist test if and only if:

$$
a \leq a^{T} \equiv b_{S}-c_{S} \quad \Leftrightarrow \quad p_{B} \geq p_{B}^{T}=c-b_{S}+m
$$

With an inelastic final demand, the different components of social welfare are:

- consumer surplus $C S=u-p-p_{B} D_{B}\left(p_{B}\right)-\int_{-\infty}^{p_{B}} b_{B} d H\left(b_{B}\right)$, where $u$ denotes the utility of the good for the consumers, $p$ is the retail price, and the integral represents the expected convenience cost of cash payments.

- retailers' profit $R P=p-\gamma-p_{S} D_{B}\left(p_{B}\right)-b_{S}\left(1-D_{B}\left(p_{B}\right)\right)$,

\footnotetext{
${ }^{8}$ Nothing prevents, both in our model and in reality, $a$ from being negative, i.e., the IF from flowing from the issuer to the acquirer.

${ }^{9}$ As in the rest of the paper, indices $B$ refer to the buyer side, and indices $S$ refer to the seller side. Thus $c_{B}$ represents the marginal cost of the issuer (the buyer's bank) and $c_{S}$ that of the acquirer (the seller's bank).
} 
- banks' profit $\pi_{B}=\left(p_{B}+p_{S}-c\right) D_{B}\left(p_{B}\right)=m D_{B}\left(p_{B}\right)$.

Adding these three components, we see that social welfare is equal (up to a constant) to:

$$
W=\int_{p_{B}}^{\infty}\left(b_{B}+b_{S}-c\right) d H\left(b_{B}\right) .
$$

Social welfare is a single-peaked function of $p_{B}$, and reaches its maximum at

$$
p_{B}^{W} \equiv c-b_{S} .
$$

The first-best price $p_{B}^{W}$ makes the consumer perfectly internalize the externality associated with the decision of paying by card. Indeed, the social cost of a card payment includes both the marginal cost $c_{B}$ of the buyer's bank and the externality $c_{S}-b_{S}$ exerted on the seller's side. Comparing with formula (6), we see that the buyer price $p_{B}$ that corresponds to the tourist test threshold is equal to the sum of $p_{B}^{W}$ and issuers' margin $m$ :

$$
p_{B}^{T}=p_{B}^{W}+m .
$$

The maximum interchange fee that passes the tourist test, $a^{T}$, thus corresponds to the socially optimal IF when banks are perfectly competitive $(m=0)$, as was first pointed out by Baxter (1983). The merchant discount corresponding to this upper bound $a^{T}$ (namely $p_{S}=c_{S}+a^{T}=b_{S}$ ) makes the retailer ex-post indifferent as to the buyer's choice of payment instrument (Farrell 2006).

When issuers have market power $(m>0)$, the socially optimal interchange fee does not pass the tourist test:

$$
a^{W}=c_{B}-p_{B}^{W}+m=b_{S}-c_{S}+m>a^{T} .
$$

Let us now turn to consumer surplus. Competition Authorities sometimes use the retail price as a proxy for consumer surplus. However, retail prices are not a good measure of consumer surplus in our context, because they do not account for transaction costs. When retailers' profit is constant (the retail price moves one for one with retail cost), the formulas for consumer surplus and retailers' profit given above show that consumer surplus is equal (up to a constant) to the following function $\phi$, which we call total user surplus:

$$
\begin{aligned}
\phi & \equiv\left(b_{S}-p_{S}\right) D_{B}\left(p_{B}\right)+\int_{p_{B}}^{\infty}\left(b_{B}-p_{B}\right) d H\left(b_{B}\right) \\
& \equiv \int_{p_{B}}^{\infty}\left(b_{B}+b_{S}-p_{B}-p_{S}\right) d H\left(b_{B}\right) .
\end{aligned}
$$


$\phi$ represents the expectation of the total surplus (total benefit $b_{B}+b_{S}$ minus total price $p_{B}+p_{S}$ ) derived from card payments by the two categories of users.

Total user surplus $\phi$ is maximized ${ }^{10}$ for a value $p_{B}^{T U S}$ that exceeds $p_{B}^{W}$ :

$$
p_{B}^{T U S}=c-b_{S}+m \geq p_{B}^{W}=c-b_{S}
$$

$p_{B}^{T U S}$ exceeds $p_{B}^{W}$ because user surplus does not include issuers' profit. Since issuers' profit $m D_{B}\left(p_{B}\right)$ decreases with $p_{B}$, a higher $p_{B}$ (and thus a lower interchange fee) implies a lower expected profit for issuers and thus, around the social welfare optimum, a higher expected total user surplus. The corresponding interchange fee $a^{T U S}$ is given by:

$$
a^{T U S}=c_{B}-p_{B}^{T U S}+m .
$$

Thus it is equal to the tourist test threshold:

$$
a^{T U S}=b_{S}-c_{S}=a^{T}
$$

The behavior of functions $W$ and $\phi$ is represented in Figure 1.

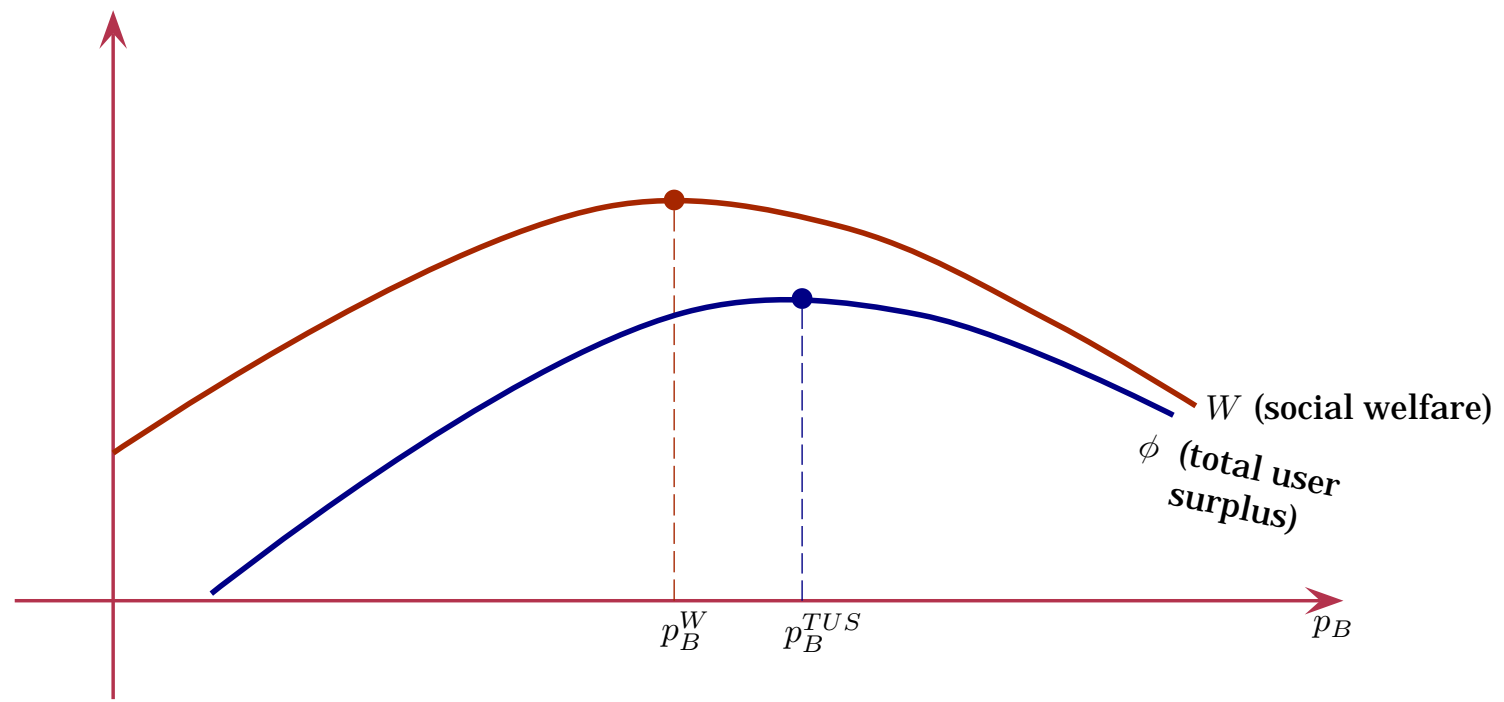

Figure 1: Total user surplus $\phi$, and social welfare $W$. The vertical difference between these functions represents the expected profit of issuers. It decreases with $p_{B}$. This explains why $p_{B}^{T U S}$, which maximizes $\phi$, is to the right of $p_{B}^{W}$, which maximizes $W$.

The following proposition summarizes our results.

\footnotetext{
${ }^{10}$ Assumption 1 implies a lower bound on cardholder fees: a retailer accepts the card only if $p_{S} \leq b_{S}+$ $v_{B}\left(p_{B}\right)$. Thus $p_{B}=c+m-p_{S}$ must be equal at least to $p_{B}^{m}$, defined implicitly by $c+m-p_{B}^{m}=b_{S}+v_{B}\left(p_{B}^{m}\right)$. Since total user surplus $\phi$ and social welfare $W$ are quasi-concave, whether this constraint binds or not does not modify the comparison between $p_{B}^{T U S}$, that maximizes $\phi$, and $p_{B}^{W}$, that maximizes $W$.
} 
Proposition 2. When issuers' margin is constant:

i) the interchange fee $a^{W}$ that maximizes social welfare offsets issuers' margin and thus is higher than the tourist test threshold $a^{T}$ :

$$
a^{W}=a^{T}+m
$$

ii) the interchange fee $a^{T U S}$ that maximizes total user surplus is equal to $a^{T}$.

Thus in the benchmark model, the tourist test detects the interchange fees that are excessive from the point of view of total user surplus, but it is too restrictive from the point of view of social welfare. ${ }^{11}$

Remark (acquirer margins): The analysis can be generalized to allow for constant acquirers' markups $m_{S}$. The total margin $m$ then equals the sum of acquirers' margin $m_{S}$ and issuers' margin $m_{B}$. With constant markups $\left(m_{B}\right.$ and $m_{S}$ invariant), the wedge between the welfare-optimal IF, which remains equal to $a^{W}=b_{S}-c_{S}+m_{B}$, and the TUS-maximizing IF, $a^{T U S}=b_{S}-\left(c_{S}+m_{S}\right)$, increases. Intuitively, the buyer internalizes his own cost, including $m_{B}$, and so in the TUS optimum, the internalization of the seller's surplus accounts for the acquiring cost, $c_{S}+m_{S}$. Note that $a^{T}=b_{S}-c_{S}-m_{S}$ still coincides with $a^{T U S}$. Thus Proposition 2 extends to a constant acquirer margin.

\subsection{Variable issuers' margin}

We now allow issuers' margin to vary with their net cost $c_{I}=c_{B}-a$. We model issuer competition in reduced form, denoting by $p_{B}\left(c_{I}\right)$ and $\pi_{B}\left(c_{I}\right)$ the issuers' price and profit as functions of $c_{I}$. We assume that $p_{B}$ increases and $\pi_{B}$ decreases with $c_{I} \cdot{ }^{12}$ Issuers' margin $m$ is a function of $p_{B}$, defined implicitly by: ${ }^{13}$

$$
m\left(p_{B}\left(c_{I}\right)\right)=p_{B}\left(c_{I}\right)-c_{I}
$$

\footnotetext{
${ }^{11}$ Appendix 6 shows that Proposition 2 generalizes to the case where final demand by consumers is elastic.

${ }^{12}$ Revealed preference implies that these conditions are always satisfied for a monopoly issuer.

${ }^{13}$ This is more general than Rochet and Tirole (2002) where we assumed $0<p_{B}^{\prime}<1$. Here we do not require $p_{B}^{\prime}<1$. The assumption that $p_{B}^{\prime}<1$ implies that $m^{\prime}<0$ (cost absorption). The case $p_{B}^{\prime}=1$ corresponds to that of a constant margin. We also consider here the case where $p_{B}^{\prime}>1$ (e.g. Cournot oligopoly with isoelastic demand). In this cost amplification case $m$ increases with $p_{B}$. Weyl (2008) calls Mark-Up Contraction (MUC) the property that we call cost absorption and shows that for a monopoly it is implied by log-concavity of demand. His paper contains a very general analysis of pass though in the case of a single downstream agent.
} 
There is cost absorption if $p_{B}^{\prime}<1$ (equivalently $m^{\prime}<0$ ) and cost amplification if $p_{B}^{\prime}>1$ (equivalently $m^{\prime}>0$ ). The benchmark case of Section 3.1 assumed cost passthrough $\left(p_{B}^{\prime}=1\right.$, that is $\left.m^{\prime}=0\right)$. Note that, in all cases, $m^{\prime}=\frac{p_{B}^{\prime}-1}{p_{B}^{\prime}}<1$.

We show in Appendix 2 that the issuers' price that maximizes total user surplus is defined implicitly by:

$$
p_{B}^{T U S}=c-b_{S}+m+\frac{m^{\prime} D_{B}}{D_{B}^{\prime}}
$$

and the corresponding IF is:

$$
a^{T U S}=a^{T}-\frac{m^{\prime} D_{B}}{D_{B}^{\prime}}
$$

Thus we have:

Proposition 3. The interchange fee $a^{T U S}$ that maximizes total user surplus is higher than $a^{T}$ in the cost amplification case $\left(m^{\prime}>0\right)$ and lower than $a^{T}$ in the cost absorption case $\left(m^{\prime}<0\right)$. In both cases, the socially optimal interchange fee $a^{W}$ exceeds $a^{T}$.

Proof of Proposition 3: See Appendix 2.

\section{Privately optimal interchange fees}

We now compute the IF that maximizes issuers' profit, first with a monopoly platform (Section 4.1) and then with competing platforms (Section 4.2). As in Section 3.2, we allow issuers' margin to vary with their net cost.

\subsection{Monopoly platform}

When $b_{S}$ is the same for all merchants and there is no platform competition, the card association sets the IF at the maximum value that retailers accept. This is because issuers' profit $m\left(p_{B}\right) D_{B}\left(p_{B}\right)$ decreases with $p_{B}$, while $p_{B}$ decreases with the $I F$. Proposition 1 then implies that the price $p_{B}^{m}$ chosen by the monopoly association is given implicitly by:

$$
p_{S}=b_{S}+v_{B}\left(p_{B}\right)
$$

Because $p_{S}=c-p_{B}+m\left(p_{B}\right)$ from formulas (5) and (10), we can rewrite this as:

$$
b_{S}-c+p_{B}-m\left(p_{B}\right)+v_{B}\left(p_{B}\right)=0 .
$$


Using formula (13), the issuers' optimal buyer price can be rewritten as:

$$
p_{B}^{m}=c-b_{S}+m\left(p_{B}^{m}\right)-v_{B}\left(p_{B}^{m}\right)
$$

Comparing (14) with formula (7) we see that $p_{B}^{m}$ may be bigger or smaller than $p_{B}^{W}=$ $c-b_{S}$, depending on issuer market power $m$ and on average cardholder benefit $v_{B}$. The interchange fee chosen by the monopoly association is thus:

$$
a^{m}=c_{B}-p_{B}^{m}+m\left(p_{B}^{m}\right)=b_{S}-c_{S}+v_{B}\left(p_{B}^{m}\right) .
$$

Proposition 4. i) A monopoly association selects the maximum interchange fee $a^{m}$ that is accepted by retailers.

ii) When $m\left(p_{B}^{W}\right)<v_{B}\left(p_{B}^{W}\right)$ (a condition that is more likely to be satisfied when issuers' margin is small, and when the net average cardholder benefit is large), $a^{m}$ is larger than the socially optimal IF.

iii) When $m\left(p_{B}^{W}\right) \geq v_{B}\left(p_{B}^{W}\right)$, the interchange fee $a^{m}$ chosen by the association coincides with the (second best) socially optimal IF.

\section{Proof of Proposition 4}

Part i) has already been noted. To establish parts ii) and iii), let us recall that social welfare is equal (up to a constant) to the sum of total user surplus and banks' profit:

$$
W=\phi+m D_{B}=\int_{p_{B}}^{\infty}\left(b_{B}+b_{S}-c\right) d H\left(b_{B}\right)
$$

which is maximum for $p_{B}=p_{B}^{W}$. Since $W$ is quasi-concave in $p_{B}$, the socially optimal buyer price is equal to $p_{B}^{W}$ when this is compatible with merchant acceptance, i.e., when $b_{S}-p_{S}^{W}+v_{B}\left(p_{B}^{W}\right)>0$, and to $p_{B}^{m}$ otherwise. Now

$$
p_{S}^{W}=c+m-p_{B}^{W}=m+b_{S},
$$

and thus

$$
b_{S}-p_{S}^{W}+v_{B}\left(p_{B}^{W}\right)=v_{B}\left(p_{B}^{W}\right)-m\left(p_{B}^{W}\right) .
$$

When this quantity is positive, merchants are ready to accept higher IFs (leading to a lower buyer price). In this case the socially optimal buyer price is $p_{B}^{W}>p_{B}^{m}$. By contrast, when $v_{B}\left(p_{B}^{W}\right)-m\left(p_{B}^{W}\right)$ is negative, $p_{S}^{W}$ is too high to be accepted by merchants. In this case the socially optimal buyer price coincides with the price $p_{B}^{m}$ chosen by the monopoly association. This establishes ii) and iii). 
Proposition 4 extends an earlier result of Rochet and Tirole (2002) to the case of an arbitrary issuers' margin. ${ }^{14}$ It shows that when there is a single association, when acquiring is perfectly competitive and when there is no unobservable heterogeneity among retailers, the association sets the highest possible IF $a^{m}$ that retailers accept. $a^{m}$ is always larger than the level $a^{T U S}$ that maximizes total user surplus (and thus consumer surplus). However it is not necessarily larger than the socially optimal IF. If issuers' margin is large, or if retailers' acceptance of cards has a limited impact on their competitive position (for example if the average benefit $v_{B}$ of cardholders per card payment is small) the interchange fee that maximizes social welfare is too large to be acceptable by retailers. The (second best) socially optimal IF then coincides with the privately optimal one. By contrast, a for-profit monopoly always chooses a price that is socially sub-optimal:

Proposition 5. A for-profit monopoly system selects prices $\left(p_{B}^{M}, p_{S}^{M}\right)$ characterized by:

$$
\begin{aligned}
\text { i) } & p_{S}^{M}=b_{S}+v_{B}\left(p_{B}^{M}\right) \\
\text { ii) } & p_{B}^{M}=c-b_{S}+\frac{\left(m D_{B}\right)^{\prime}}{D_{B}^{\prime}}\left(p_{B}^{M}\right) .
\end{aligned}
$$

i) means that total user surplus is equal to zero, ${ }^{15}$ while ii) implies that $p_{B}^{M}=p_{B}^{T U S}>p_{B}^{W}$ (too few card transactions).

Proof of Proposition 5: The profit of the platform is

$$
\pi=\left(p_{B}+p_{S}-c-m\left(p_{B}\right)\right) D_{B}\left(p_{B}\right)
$$

A for-profit monopoly platform chooses $\left(p_{B}, p_{S}\right)$ that maximizes $\pi$ under the constraint that retailers accept cards: $p_{S} \leq b_{S}+v_{B}\left(p_{B}\right)$. Since $\pi$ increases with $p_{S}$, this constraint binds, which establishes $i$ ). Thus we can replace $p_{S}$ by $b_{S}+v_{B}\left(p_{B}\right)$. This implies that $\pi$ is equal to $\phi$ :

$$
\pi=\int_{p_{B}}^{\infty}\left[b_{S}+b_{B}-c-m\left(p_{B}\right)\right] d H\left(b_{B}\right)=\phi .
$$

Thus $p_{B}^{M}=p_{B}^{T U S}$. Using formula (11), we obtain ii).

\footnotetext{
${ }^{14}$ We relax the assumption of "cost absorption" by issuers (see footnote 13 ).

${ }^{15}$ Remember that costs and benefits are measured with respect to the alternative payment instrument (cash). i) means that a for-profit monopoly extracts all the surplus generated by the card.
} 


\subsection{Platform competition}

We now extend our analysis to the competition between two card associations (indexed by $k=1,2)$ in the context of the Hotelling-Lerner-Salop model of retailing.

For simplicity we assume that the two cards are perfect substitutes for both buyers and sellers. The two associations compete by setting IFs $a_{1}$ and $a_{2}$, which in turn determine user prices (denoted $p_{B}^{k}$ and $p_{S}^{k}, k=1,2$ ). We can characterize retailers' acceptance decisions by looking at total user surplus $\phi$.

As shown in Appendix 3, a retailer's optimal decision is to accept the set of cards that maximizes the expected value of $\phi$ among consumers. This expected value depends in turn on the proportion of consumers who hold both cards (we call such consumers multihomers) and on the proportion of consumers who hold only one of them (single-homers).

A complete analysis of platform competition lies outside the scope of this paper. We content ourselves with the analysis of two polar cases: Subsection 4.2.1 looks at the case of complete multi-homing, and Subsection 4.2.2 studies complete single-homing. Guthrie and Wright (2007) analyze a more general model of platform competition, where cardholders' multi-homing decision is endogenized. They show that equilibrium IFs are always in between the ones obtained in the two polar cases of complete multi-homing and complete single-homing. Appendix 3 analyzes the retailers' acceptance decision under partial multi-homing.

\subsubsection{Complete multi-homing}

We show in Appendix 3 that, when all consumers have the two cards, the retailers' equilibrium acceptance policy is: ${ }^{16}$

- Accept both cards if $\phi\left(p_{B}^{1}\right)=\phi\left(p_{B}^{2}\right) \geq 0$.

- Accept only the one that attains $\max \left(\phi\left(p_{B}^{1}\right), \phi\left(p_{B}^{2}\right)\right)$ if this maximum is positive.

- Accept none if this maximum is negative.

By symmetry the competition between networks results in (equal) prices, set to maximize $\phi\left(p_{B}\right) .{ }^{17}$

\footnotetext{
${ }^{16}$ This condition is a particular case of the general condition (37) obtained in Proposition 13, Appendix 3. It corresponds to a proportion of multi-homers $\beta_{12}$ equal to 1 (and thus $\beta_{1}=\beta_{2}=0$ ).

${ }^{17}$ This is the two-sided version of Bertrand's undercutting argument.
} 
Proposition 6. In the case of complete multi-homing (all consumers have the two cards), both associations set the same interchange fee, $a^{M H}=a^{T U S}$. Therefore $a^{M H} \leq a^{T}$ if and only if $m^{\prime}\left(p_{B}\right) \leq 0$.

Thus the interchange fee set by competing networks is equal to the value that maximizes total user surplus. Furthermore, the interchange fee passes the tourist test provided that either there is cost absorption or passthrough by issuers $\left(m^{\prime}\left(p_{B}\right) \leq 0\right)$.

We now examine the polar case of complete single-homing.

\subsubsection{Complete single-homing}

If all consumers have a single card each, card $i$ is accepted if and only if ${ }^{18} \phi\left(p_{B}^{i}\right) \geq 0$. This implies that, as with a single network, card associations select the highest IF $a^{S H}$ that retailers accept. The outcome of network competition is the same as the monopoly outcome characterized in Proposition 4:

- The price $p_{B}^{S H}$ paid by cardholders is characterized implicitly by $\phi\left(p_{B}^{S H}\right)=0$, which gives:

$$
p_{B}^{S H}=c-b_{S}+m\left(p_{B}^{S H}\right)-v_{B}\left(p_{B}^{S H}\right)=p_{B}^{m}
$$

- As illustrated by Figure 2, this price is lower than the value $p_{B}^{T U S}$ that maximizes consumer surplus (or equivalently total user surplus) when issuers' margin decreases with $p_{B}$ (cost absorption case). ${ }^{19}$

Proposition 7. Under complete single-homing, the interchange fee $a^{\text {SH }}$ set by competing networks is equal to the monopoly interchange fee $a^{m} . a^{S H}$ is thus larger than or equal to the socially optimal IF, equal to $\min \left(a^{m}, a^{W}\right)$.

\footnotetext{
${ }^{18}$ This condition is a particular case of the general condition (37) obtained in Proposition 13, Appendix 3. It corresponds to a proportion of multi-homers $\beta_{12}$ equal to 0 .

${ }^{19}$ However the reverse may hold when issuers' margin increases with $p_{B}$ (cost amplification case).
} 


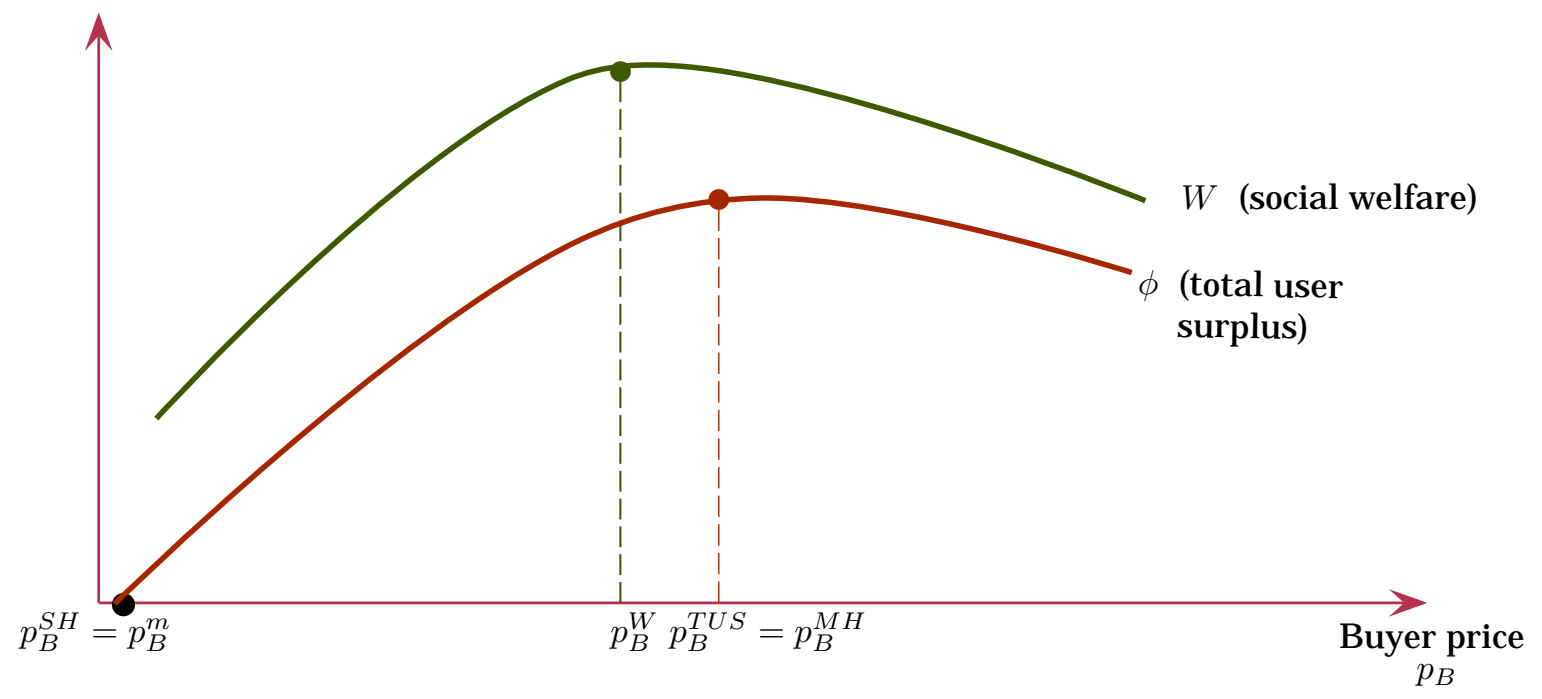

Figure 2: Comparison of buyer prices (in the cost absorption case) when two card associations compete:

- when consumers singlehome, the outcome is $p_{B}^{S H}$ (i.e, the same as in the case of a single network),

- when consumers multi-home, the outcome is $p_{B}^{M H}$. It is equal to the price $p_{B}^{T U S}$ that maximizes total user surpl us in the cost absorption case (as represented here) and lower in the cost amplification case

\subsection{Comparing socially optimal and privately optimal IFs:}

We can now summarize the results and compare socially optimal and privately optimal IFs as a function of the intensity of issuers' competition.

In the case of perfect (Bertrand) competition among issuers $(m=0)$, the tourist test and the welfare and TUS thresholds coincide, as shown in Figure 3. When two cards associations compete, the outcome is equal to $a^{T}$ when cardholders multihome $(M H)$ and to the monopoly outcome $a^{m}$ if they single-home $(S H)$.

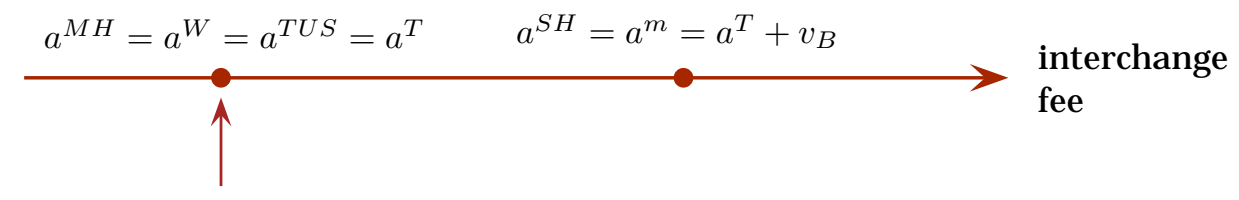

$$
\begin{aligned}
& \text { tourist test; } \\
& \text { welfare and } \\
& \text { consumer } \\
& \text { surplus } \\
& \text { optima. }
\end{aligned}
$$

Figure 3: The perfect competition case $(m=0)$ 
Under perfect issuer competition, privately optimal IFs, that always lie in the interval $\left(a^{M H}, a^{S H}\right)$ are (weakly) higher than the socially optimal IF $\left(a^{W}=a^{T U S}\right)$, which coincides with the tourist test threshold $a^{T}$. Thus if issuer competition were perfect, it would be legitimate to cap the IF at $a^{W}$ and use the tourist test as a check.

However, under the more reasonable assumption that issuers have some ex post market power (which seems to be the working hypothesis of Competition Authorities in many regions of the world), the analysis is more complex. When issuers' margin is constant (and not too big) the situation is represented in Figure $4 .^{20}$

Under imperfect issuer competition, the tourist test threshold again coincides with the total user surplus optimum but this time the socially optimal IF (which internalizes issuers' profit) is higher. The competitive IF lies in the interval $\left(a^{M H}, a^{S H}\right)$ : it is therefore always (weakly) higher than $a^{T U S}$ but may be higher or lower than $a^{W}$. If Competition Authorities aim at maximizing consumer surplus, a cap based on the tourist test threshold is still warranted. This is not the case if the objective is to maximize social welfare.

When issuers' margin is not constant, the tourist test threshold does not coincide anymore with the interchange fee that maximizes total user surplus. As shown in Proposition 3 , it is higher when $m^{\prime}>0$ (cost amplification) and lower when $m^{\prime}<0$ (cost absorption).

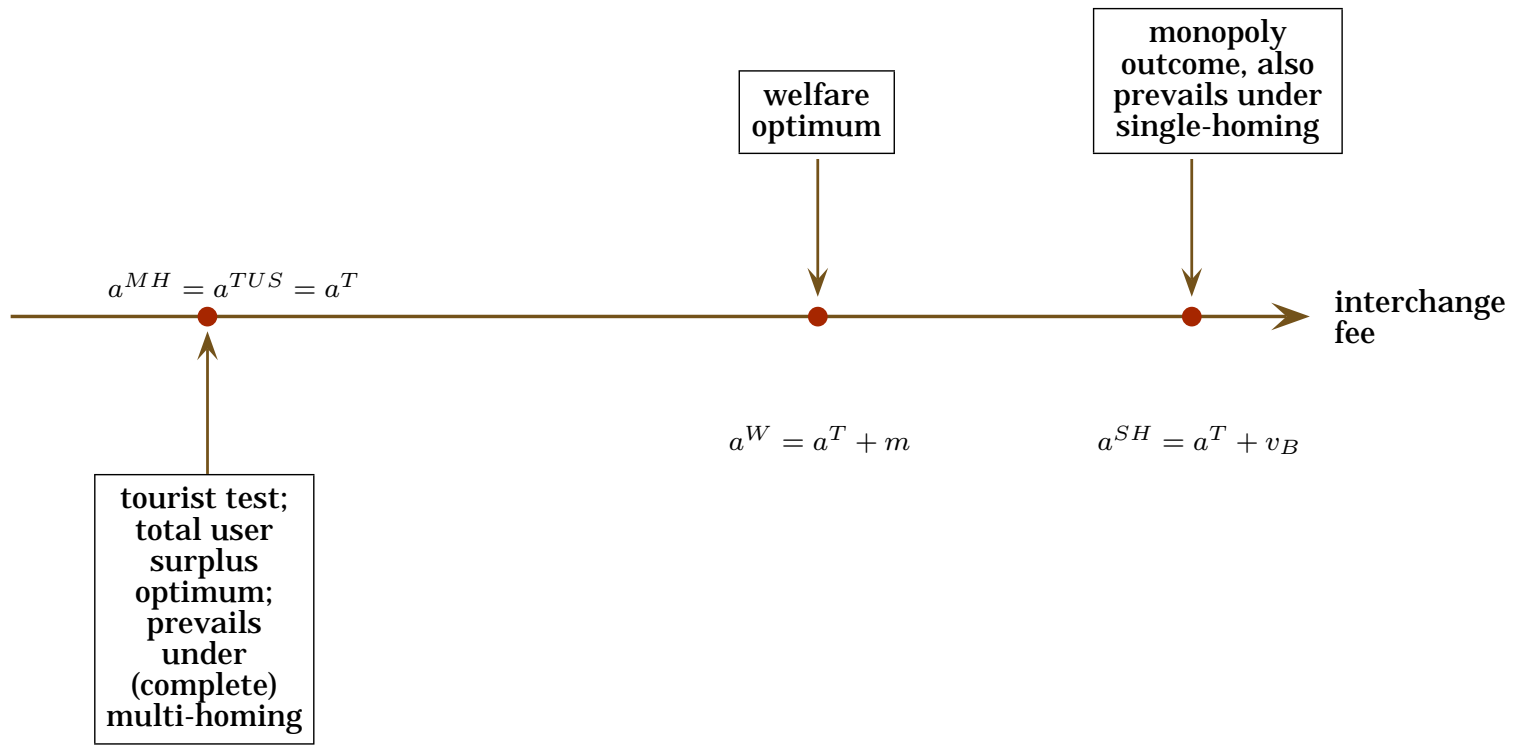

Figure 4: Constant issuer margin $(m>0)$

\footnotetext{
${ }^{20}$ When $m>v_{B}\left(p_{B}\right)$, the first-best IF $a^{W}$ is not accepted by merchants: the second-best IF coincides with the monopoly outcome $a^{m}$.
} 


\section{Entry: revisiting the notion of total user surplus}

The previous sections analyzed the interchange fees associated with two benchmarks, corresponding to the maximization of social welfare and to that of consumer surplus $(T U S)$. Focusing on the narrow notion of consumer surplus is legitimate for a shortterm analysis as long as the welfare of shareholders is weighted much less heavily than that of consumers. In the medium and long term, though, issuers respond to increased profitability by offering a wider variety of products or by reducing prices, for example under the pressure of new entrants.

To illustrate the impact of entry, this section computes the "long-term total user surplus" first in the context of an homogeneous issuing industry in which issuers do not compete perfectly (so entry reduces price but does not increase variety), then in a context of contestable issuing sub-markets. While these environments are special, they in a sense are polar cases. The homogeneous-good case confers limited benefits on the entry mechanism: While entry benefits consumers through lower prices, the incentive to enter comes in large part from business stealing. Indeed, Mankiw and Whinston (1986) show that in an homogeneous-good, free-entry industry, the equilibrium number of firms under free entry is in general larger than the efficient number. To be precise, it always exceeds the efficient number minus 1. Contestable issuing sub-markets by contrast rule out any business stealing, and thereby focus on pure product creation. Thus the former (latter) environment is rather unfavorable (favorable) to a social accounting of the benefits from entry.

\subsection{Homogeneous issuing industry}

Let $c_{I} \equiv c_{B}-a=c-p_{S}$ denote the issuers' marginal cost, and $N$ the number of issuers. The fixed cost of being in the issuing industry is $F>0$. Adapting our previous notation to account for the number $N$ of issuers, we denote by $p_{B}=p_{B}\left(c_{I}, N\right)$ and $m=m\left(p_{B}, N\right)$ the equilibrium price and margin ${ }^{21}$ for a fixed number $N$ of issuers. We assume that keeping the cardholder fee $p_{B}$ constant, the issuer margin decreases with the number of issuers: $\frac{\partial m}{\partial N}<0$ (competition reduces margins). The number of issuers is now endogenous,

\footnotetext{
${ }^{21}$ For convenience, $m$ is expressed as a function of $p_{B}$ and $N$. This is legitimate since, for $N$ given, $p_{B}$ and $c_{I}$ are in a one-to-one relation with each other.
} 
and given by the unique solution ${ }^{22} N=N\left(p_{B}\right)$ to the zero-profit equation:

$$
m\left(p_{B}, N\right) D_{B}\left(p_{B}\right)=N F
$$

Note that, from our assumption that issuers' profit $m\left(p_{B}, N\right) D\left(p_{B}\right)$ decreases with $p_{B}(N$ being constant), the number of issuers $N\left(p_{B}\right)$ also decreases with $p_{B}$.

The long-term total user surplus (also equal to social welfare since issuers in the long term make no supra-normal profit) is equal to the sum of cardholder and merchant surpluses:

$$
T U S^{L T}=\int_{p_{B}}^{\infty}\left[b_{B}+b_{S}-c-m\left(p_{B}, N\left(p_{B}\right)\right)\right] d H\left(b_{B}\right) .
$$

The only difference with short-term total user surplus $\phi$ (see formula (36)) is that the margin $m\left(p_{B}\right)$ depends on $p_{B}$ also through the number $N$ of issuers. TU $S^{L T}$ is maximized for

$$
p_{B}^{*}=c-b_{S}+m+\frac{D_{B}}{D_{B}^{\prime}}\left[\frac{\partial m}{\partial p_{B}}+\frac{\partial m}{\partial N} N^{\prime}\right] .
$$

Comparing with $p_{B}^{T U S}$ (given by formula (11)), that maximizes short-term total user surplus $\phi$, we see that $p_{B}^{*}$ contains an additional term $\frac{D_{B}}{D_{B}^{\prime}} \frac{\partial m}{\partial N} N^{\prime}$, corresponding to the impact of $p_{B}$ on the number of issuers, and thus indirectly on the level of issuers' margin. This additional term is negative since $D_{B}^{\prime}, \frac{\partial m}{\partial N}$ and $N^{\prime}$ are all negative. Thus

$$
p_{B}^{*}<p_{B}^{T U S}
$$

The intuition for this result is that a lower net issuer cost $c_{I}=c_{B}-a$ (and thus a lower cardholder fee $p_{B}$ ) increases entry and competition in the issuing market, and thereby reduces issuers' margin.

Note also that $p_{B}^{*}>p_{B}^{T}=c-b_{S}+m\left(p_{B}^{T}\right)$ if and only if there is long-term cost absorption:

$$
\left[\frac{\partial m}{\partial p_{B}}+\frac{\partial m}{\partial N} N^{\prime}\right]<0
$$

Long-term cost absorption is less likely to prevail than short-term cost absorption $\left(\frac{\partial m}{\partial p_{B}}<0\right)$, as the second term is positive.

To compare $p_{B}^{*}$ and $p_{B}^{W}=c-b_{S}$ (that maximizes short-term welfare), differentiate the zero-profit condition that defines $N\left(p_{B}\right)$ :

$$
m\left(p_{B}, N\left(p_{B}\right)\right) D\left(p_{B}\right)=N\left(p_{B}\right) F,
$$

\footnotetext{
${ }^{22}$ We neglect the constraint that $N$ is an integer.
} 
yielding:

$$
\left(\frac{\partial m}{\partial p_{B}}+\frac{\partial m}{\partial N} N^{\prime}\right) D_{B}+m D_{B}^{\prime}=N^{\prime} F
$$

Now

$$
p_{B}^{*}-p_{B}^{W}=p_{B}^{*}-c+b_{S} .
$$

By using formula (17) defining $p_{B}^{*}$, we get:

$$
p_{B}^{*}-p_{B}^{W}=m+\frac{D_{B}}{D_{B}^{\prime}}\left(\frac{\partial m}{\partial p_{B}}+\frac{\partial m}{\partial N} N^{\prime}\right)=\frac{1}{D_{B}^{\prime}}\left[m D_{B}^{\prime}+D_{B}\left(\frac{\partial m}{\partial p_{B}}+\frac{\partial m}{\partial N} N^{\prime}\right)\right] .
$$

where the right-hand side is computed at $p_{B}^{*}$. Comparing with (18), we see that:

$$
p_{B}^{*}-p_{B}^{W}=\frac{N^{\prime}}{D_{B}^{\prime}} F>0 .
$$

We can now state our results in terms of the associated interchange fees $a^{*}, a^{T U S}$ and $a^{W}$.

Proposition 8. For an homogeneous issuing industry with free entry, the long-term totaluser surplus maximizing interchange fee $a^{*}$ lies in between $a^{T U S}$, that maximizes shortterm total-user-surplus, and $a^{W}$, the short-term first best:

$$
a^{T U S}<a^{*}<a^{W} .
$$

$a^{*}$ passes the tourist test $\left(a^{*} \leq a^{T}\right)$ if there is long-term cost absorption $\left(m\left(p_{B}, N\left(p_{B}\right)\right)\right.$ decreasing) and fails it in case of long-term cost amplification $\left(m\left(p_{B}, N\left(p_{B}\right)\right)\right.$ increasing).

As already noted, long-term cost absorption is less likely to prevail than short-term cost absorption. This is illustrated by the following example. Consider Cournot competition with linear demand: $D_{B}\left(p_{B}\right)=1-p_{B}$. The industry is viable if the monopoly profit $\left(\frac{1-c_{I}}{2}\right)^{2}$ exceeds entry cost $F$. In this case the short-term equilibrium price and the short-term margin are:

$$
p_{B}\left(c_{I}, N\right)=\frac{1+N c_{I}}{1+N} \text { and } m\left(p_{B}, N\right)=p_{B}-c_{I}=p_{B}-\frac{(1+N) p_{B}-1}{N}=\frac{1-p_{B}}{N} .
$$

Thus there is short-term cost absorption $\left(\frac{\partial m}{\partial p_{B}}<0\right)$, implying, by formula (9):

$$
a^{T U S}=a^{T}-\left(\frac{\frac{\partial m}{\partial p_{B}} \cdot D_{B}}{D_{B}^{\prime}}\right)\left(p_{B}^{T U S}\right)<a^{T} .
$$


By contrast, there is long-term cost passthrough. Indeed, the zero-profit condition,

$$
m\left(p_{B}, N\right)\left(1-p_{B}\right)=N F
$$

yields :

$$
m\left(p_{B}, N\left(p_{B}\right)\right)=\sqrt{F},
$$

which is independent of $p_{B}$. Thus long-term total user surplus is maximized for $a^{*}=a^{T}=$ $b_{S}-c_{S}<a^{W}=b_{S}-c_{S}+\sqrt{F}$. Thus the tourist test threshold $a^{T}$ coincides with the IF $a^{*}$ that maximizes long-term total user surplus.

\subsection{Pure product variety}

To illustrate the product-diversity argument, we build a stylized example that does not embody any business stealing effect. Consider a continuum of niche markets for cards, indexed by the fixed cost of entry $F$. All markets are identical but for the fixed cost of entry. Let $K(F)$ denote the cumulative distribution function of $F$.

Each market is contestable (is an "auction market"). In equilibrium of a contestable market, there is a single firm, and this firm makes no profit; the markup $m\left(c_{I}, F\right)$ is the smallest solution of:

$$
m D_{B}\left(c_{I}+m\right)=F \text {. }
$$

As $\frac{d}{d m}\left(m D_{B}\left(c_{I}+m\right)\right)>0$ in the relevant range, the contestable market example exhibits long-term cost amplification ${ }^{23}\left(\frac{\partial m}{\partial c_{I}}>0\right)$.

Let $F^{*}\left(c_{I}\right)$, a decreasing function, be defined by:

$$
\max _{m}\left\{m D_{B}\left(c_{I}+m\right)\right\}=F^{*}\left(c_{I}\right)
$$

It corresponds to the maximum fixed cost that an issuer can sustain. $K\left[F^{*}\left(c_{I}\right)\right]$ represents the mass of active issuers.

Note that

$$
b_{S}-p_{S}=b_{S}-c_{S}-a=a^{T}-a .
$$

${ }^{23}$ Total differentiation of (20) gives indeed:

$$
\frac{d}{d m}\left(m D_{B}\left(c_{I}+m\right)\right) \frac{\partial m}{\partial c_{I}}+m D_{B}^{\prime}\left(c_{I}+m\right)=0 .
$$

The result follows from $D_{B}^{\prime}<0$. 
Then

$$
\begin{aligned}
T U S^{L T} & =\int_{0}^{F^{*}\left(c_{I}\right)}\left[v_{B}\left(c_{I}+m\left(c_{I}, F\right)\right)+\left(b_{S}-p_{S}\right)\right] D_{B}\left(c_{I}+m\left(c_{I}, F\right)\right) d K(F) \\
& =\int_{0}^{F^{*}\left(c_{I}\right)}\left[v_{B}\left(c_{I}+m\left(c_{I}, F\right)\right)+\left(c_{I}-c_{I}^{T}\right)\right] D_{B}\left(c_{I}+m\left(c_{I}, F\right)\right) d K(F),
\end{aligned}
$$

where $c_{I}=c_{B}-a$ and $c_{I}^{T} \equiv c_{B}-a^{T}$.

Using

$$
v_{B} D_{B}=\int_{c_{I}+m\left(c_{I}, F\right)}^{\infty}\left[b_{B}-\left[c_{I}+m\left(c_{I}, F\right)\right]\right] d H\left(b_{B}\right)
$$

we see that

$$
T U S^{L T}=\int_{0}^{F^{*}\left(c_{I}\right)} \int_{c_{I}+m\left(c_{I}, F\right)}^{\infty}\left[b_{B}-m\left(c_{I}, F\right)-c_{I}^{T}\right] d H\left(b_{B}\right) d K(F) .
$$

Then at $c_{I}=c_{I}^{T}$ :

$$
\begin{aligned}
\frac{d T U S^{L T}}{d c_{I}}= & \frac{d F^{*}}{d c_{I}}\left[\int_{c_{I}^{T}+m\left(c_{I}^{T}, F\right)}^{\infty}\left[b_{B}-m\left(c_{I}^{T}, F\right)-c_{I}^{T}\right] d H\left(b_{B}\right)\right] k\left(F^{*}\right) \\
& -\int_{0}^{F^{*}\left(c_{I}^{T}\right)} \int_{c_{I}^{T}+m\left(c_{I}^{T}, F\right)}^{\infty} \frac{\partial m}{\partial c_{I}} d H\left(b_{B}\right) d K(F) \\
= & \frac{d F^{*}}{d c_{I}} v_{B} D_{B} k\left(F^{*}\right)-\int_{0}^{F^{*}\left(c_{I}^{T}\right)} D_{B} \frac{\partial m}{\partial c_{I}} d K(F)<0
\end{aligned}
$$

(where $F^{*} \equiv F^{*}\left(c_{I}\right)$ ). Thus long-term total user surplus increases when $c_{I}$ is reduced below $c_{I}^{I}$ (i.e. $a$ increased over $a^{T}$ ).

Proposition 9. The long-term total-user-surplus maximizing interchange fee in the pureproduct-variety model always exceeds the level given by the tourist test: $a^{*}>a^{T}$.

\section{Heterogenous retailers}

As a further robustness check, we introduce unobservable heterogeneity in the retailers' convenience benefit $b_{S}$. Following Schmalensee (2002), we assume that sellers' convenience benefit is drawn from a continuous distribution with c.d.f. $G$ :

$$
G\left(b_{S}\right)=\operatorname{Pr}\left(\widetilde{b}_{S} \leq b_{S}\right)
$$

Following Wright (2004), we assume that the retail sector consists in a continuum of subsectors, each corresponding to a value of $b_{S}$. The platform however does not have 
enough information to discriminate among retailers, and thus sets a uniform interchange fee. Merchants know their individual $b_{S}$ before accepting cards. The buyers' distribution of convenience benefits, $H\left(b_{B}\right)$, is independent of the market in which they buy. Consumers buy one good in each of these markets and patronize the store that offers the best combination of retail price, transportation cost and quality of service (determined here by the retailer's decision of whether to accept cards). For given prices for card services $\left(p_{B}\right.$ and $\left.p_{S}\right)$, the retailer's equilibrium behavior is characterized by condition (3), but now this behavior is conditional on the realization of $b_{S}$ : A retailer in "subsector" $b_{S}$ accepts card payments if and only if:

$$
b_{S} \geq \widehat{b}_{S} \equiv p_{S}-v_{B}\left(p_{B}\right)
$$

Let $v_{S}\left(\widehat{b}_{S}\right)$ denote the average retailer surplus per card payment:

$$
v_{S}\left(\widehat{b}_{S}\right) \equiv \frac{\int_{\hat{b}_{S}}^{\infty}\left(b_{S}-\widehat{b}_{S}\right) d G\left(b_{S}\right)}{1-G\left(\widehat{b}_{S}\right)}=E\left(b_{S}-\widehat{b}_{S} \mid b_{S} \geq \widehat{b}_{S}\right) .
$$

The volume of card transactions is easily computed:

$$
V=D_{B}\left(p_{B}\right) D_{S}\left(\widehat{b}_{S}\right)
$$

where $D_{S}\left(\widehat{b}_{S}\right)=1-G\left(\widehat{b}_{S}\right)$ represents the "demand" for card transactions by retailers. ${ }^{24}$

\subsection{Socially optimal interchange fees}

Social welfare is maximized when two symmetric "Samuelson conditions" are satisfied:

$$
p_{B}^{*}=c-E\left[b_{S} \mid b_{S} \geq \widehat{b}_{S}\right]
$$

and

$$
\widehat{b}_{S}=c-E\left[b_{B} \mid b_{B} \geq p_{B}^{*}\right]
$$

These Samuelson conditions imply a "balanced externality condition": expected surpluses per card payment are equal for buyers and sellers. Indeed, taking the difference between the two Samuelson conditions above gives:

$$
p_{B}^{*}-\widehat{b}_{S}=E\left[b_{B} \mid b_{B} \geq p_{B}^{*}\right]-E\left[b_{S} \mid b_{S} \geq \widehat{b}_{S}\right]
$$

\footnotetext{
${ }^{24} \mathrm{~A}$ similar multiplicative formula for the volume of card transactions (with $\alpha=0$ and thus $\widehat{b}_{S}=p_{S}$ ) was first proposed by Schmalensee (2002) and later used in a more general context by Rochet and Tirole (2003).
} 
Now, recall that the buyers' expected surplus equals

$$
v_{B}\left(p_{B}^{*}\right) \equiv E\left[b_{B}-p_{B}^{*} \mid b_{B} \geq p_{B}^{*}\right]
$$

We obtain:

$$
v_{B}\left(p_{B}^{*}\right)=v_{S}\left(\widehat{b}_{S}\right) \equiv E\left[b_{S}-\widehat{b}_{S} \mid b_{S} \geq \widehat{b}_{S}\right]
$$

where $v_{S}\left(\widehat{b}_{S}\right)$ equals the expected surplus of sellers per card payment.

When $m=0$ (perfect competition among issuers), this social optimum can be implemented by setting the interchange fee at:

$$
a^{*}=c_{B}-p_{B}^{*}=E\left[b_{S} \mid b_{S} \geq \widehat{b}_{S}\right]-c_{S} .
$$

This is because merchants fully internalize cardholder surplus (so the second Samuelson condition is met $^{25}$ ).

The corresponding merchant discount is

$$
p_{S}=E\left[b_{S} \mid b_{S} \geq \widehat{b}_{S}\right]
$$

In this case the average merchant (among those who accept cards) is ex post indifferent as to the means of payment chosen by the consumer. This implies that unless all retailers are identical, some would want to reject cards ex post. Efficiency cannot require that the tourist test be met by all participating merchants because cardholders must internalize the welfare of the average merchant and not of the marginal one, who values card payments less than the average merchant. Capping merchant discounts at the convenience benefit of the most reluctant merchants provides the cardholder with an incentive for underconsumption of card payments. The next proposition summarizes these results and considers the more general case where issuers' margin $m$ is positive, but constant.

Proposition 10. Assume that merchants differ in the net convenience benefit $b_{S}$ that they derive from card transactions and that issuers' margin is constant (perfect cost passthrough).

i) The socially optimal prices $\left(p_{B}^{W}, p_{S}^{W}\right)$ are characterized by:

$$
\frac{D_{B}^{\prime}}{D_{B}}\left[v_{S}+\left[m-v_{B}\right]\right]=\frac{D_{S}^{\prime}}{D_{S}}\left[1+v_{B}^{\prime}\right]\left[v_{B}+\left[m-v_{B}\right]\right]
$$

\footnotetext{
${ }^{25}$ This condition is $\widehat{b}_{S}=c-E\left(b_{B} \mid b_{B} \geq p_{B}^{*}\right)=c-p_{B}-v_{B}\left(p_{B}^{*}\right)$. When $p_{B}+p_{S}=c$, this condition coincides with the definition of $\widehat{b}_{S}$ (condition $(21)$ ).
} 
where $D_{B}=D_{B}\left(p_{B}^{W}\right), v_{B}=v_{B}\left(p_{B}^{W}\right)$ and $v_{S}=v_{S}\left(\widehat{b}_{S}^{W}\right)$.

ii) The user prices $\left(p_{B}^{T U S}, p_{S}^{T U S}\right)$ that maximize total user surplus are characterized by the "balanced externality condition":

$$
v_{S}\left(\widehat{b}_{S}^{T U S}\right)=v_{B}\left(p_{B}^{T U S}\right)
$$

This can be implemented by selecting a merchant discount equal to the average convenience benefit among the merchants who accept cards.

Note that for $m=0$, condition (23) yields the balanced externality condition (24).

Proof of Proposition 10: See Appendix 4.

Proposition 10 shows how the "optimal balancing" condition $\frac{D_{B}^{\prime}}{D_{B}} v_{S}=\frac{D_{S}^{\prime}}{D_{S}} v_{B}$ obtained in Rochet-Tirole (2003) must be amended to reflect internalization and market power. For an association, a decrease in price on one side must be offset by an equal increase of price on the other side. Losing, say, one seller implies a waste of surplus $v_{B}$ on the buyer side, and conversely. This explains the basic optimal balancing formula. To understand how internalization and market power modify this formula, note first that an increase in $p_{S}$ has two effects on seller demand as it leads to an equal ${ }^{26}$ decrease in $p_{B}$ and thus in a perceived increase in quality of service $\left|v_{B}^{\prime}\right|$. Thus everything is as if the net price increase on the seller side were $1+v_{B}^{\prime}<1$, or, put differently, as if the elasticity on the seller side had been scaled down by this factor. Second, the surpluses $v_{j}$ on side $j \in\{B, S\}$ created by increased demand on side $i$ become $v_{j}+\left[m-v_{B}\right]$; the correction is equal to the markup $m$ (the issuers' "surplus") minus the buyers' surplus which is already internalized by the sellers. ${ }^{27}$

\subsection{Privately optimal interchange fees}

Let us now compare the payment system's choice of interchange fee with the TUS and welfare benchmarks obtained above. The following result (whose proof can be found in Appendix 5) assumes that the issuers' margin $m$ is constant, so that $p_{B}+p_{S}$, equal to $c+m$, is itself a constant.

Proposition 11. Assume that merchants differ in the net convenience benefit $b_{S}$ that they derive from card transactions and that issuers' margin is constant (perfect cost

\footnotetext{
${ }^{26}$ This is because this section assumes constant issuers' margin.

${ }^{27}$ The difference $m-v_{B}$ also played an important role in Proposition 4.
} 
passthrough).

i) Provided that social welfare is quasi-concave in the buyer price, the IF selected by a monopoly association is lower than the socially optimal value if and only if average merchant surplus per card payment exceeds cardholders':

$$
v_{S}\left(\widehat{b}_{S}^{m}\right)>v_{B}\left(p_{B}^{m}\right)
$$

ii) This condition is equivalent to the "average tourist test" $\left(p_{S}<E\left(b_{S} \mid b_{S}>\widehat{b}_{S}\right)\right)$.

iii) When total user surplus is quasi-concave in the buyer price, this condition is also necessary and sufficient for the monopoly IF to be lower than the value that maximizes total user surplus.

Proposition 11 shows that when the merchant homogeneity assumption is relaxed, the price structure chosen by a monopoly platform, in the absence of a regulation, is no longer systematically biased in favor of cardholders. ${ }^{28}$ Intuitively, issuers want to maximize volume and do not account for buyer and seller surpluses. The bias induced by a private choice of IF depends on the relative surplus of the two groups of users. When the average net benefit of retailers from card payments $v_{S}$ is greater than the average net benefit of consumers $v_{B}$, the IF chosen by a monopoly platform is too low, from both viewpoints of social welfare and total user surplus.

To prove Proposition 11 (see Appendix 4), one first demonstrates that in the absence of IF regulation, a monopoly network chooses the price structure $\left(p_{B}^{m}, p_{S}^{m}\right)$ that maximizes volume $V=D_{B} D_{S}$ subject to $p_{B}+p_{S}$ being constant. It is characterized by the equality of the semi-elasticities, where the sellers' semi-elasticity must be reduced to account for their internalization of buyer surplus:

$$
\frac{D_{B}^{\prime}}{D_{B}}\left(p_{B}^{m}\right)=\frac{D_{S}^{\prime}}{D_{S}}\left(\widehat{b}_{S}^{m}\right)\left[1+v_{B}^{\prime}\right]
$$

\section{Conclusion}

This paper has shown that Vickers (2005)'s "must-take cards" argument should be taken seriously. Due to their internalization of some fraction of buyer surplus, retailers may indeed end up accepting cards that raise their operating costs. Yet, this internalization need not be detrimental to social welfare. Two polar cases must be considered.

\footnotetext{
${ }^{28}$ Condition (25) is never satisfied when merchants are homogeneous. As established by Proposition 4, the monopoly IF is then higher than or equal to the socially optimal IF, which is consistent with Proposition 11.
} 
Under merchant homogeneity and in the absence of platform competition (or under cardholder single-homing), the interchange fee chosen by issuers exceeds the short-term socially optimal level if and only if cardholder benefits (or at least the fraction of them internalized by merchants) exceed the issuers' per transaction markup. Under platform competition and multi-homing, the IF is smaller than the value that maximizes short-term total user surplus (TUS, equal to cardholders' plus merchants' surplus, i.e. not including issuer markups), and a fortiori the value that maximizes social welfare.

When issuer margins are constant and merchants are homogenous, the tourist test is a proper and practical policy tool. By definition, the tourist test fails whenever retailers would want to refuse a card payment by a non-repeat customer with enough cash in her pocket. This implies that the IF lies above the level that maximizes short-term total user surplus, thus indicating that platform competition is insufficient or that cardholder single-homing is prevalent. A key result of this paper is thus that, with constant issuer margins and homogenous merchants, a regulatory cap based on merchants' avoided cost is legitimate when competition authorities aim at maximizing short-term total user surplus.

We also studied the robustness of this result and identified three reasons why the tourist test may yield false positives even if we focus on TUS.

First, in the short run, the TUS-maximizing IF fails the tourist test if the issuing industry's prices exhibit cost amplification (conversely, cost absorption leads to false negatives). Second, in the long term, issuer markups translate into entry and thereby lower prices and increased variety, and so the short-term analysis yields TUS-maximizing IFs that are smaller than their long-term counterpart. Third, merchants are heterogenous, and an IF that properly guides cardholders' decisions must reflect the average, not the marginal merchant benefit. This implies that the merchants who benefit least from the card, say the large retailers, are likely to fail the tourist test at the social optimum.

An indirect contribution of the paper has been to supply a theoretical framework in which platforms' business strategies and antitrust concerns can be taken to the data. Besides its two-sidedness, a novel and central aspect of the environment considered here is the internalization of buyer surplus by sellers. The identification of supply and demand functions and the estimation of welfare are policy relevant and intellectually challenging questions on the empirical agenda. 


\section{References}

[1] Balto, D. A.(2000) "The Problem of Interchange Fees: Costs without Benefits?" European Competition Law Review, 21(4): 215-224.

[2] Baxter, W.P. (1983), "Bank Interchange of Transactional Paper: Legal Perspectives" Journal of Law and Economics, 26, 541-588.

[3] Carlton, D. W., and A.S. Frankel (1995) "The Antitrust Economics of Credit Card Networks," Antitrust Law Journal, 63(2): 643-668.

[4] Chang, H. H., and D.S. Evans (2000) "The Competitive Effects of the Collective Setting of Interchange Fees by Payment Card Systems," Antitrust Bulletin, 45(3): $641-677$.

[5] Evans, D. S., and R. Schmalensee (1995) "Economic Aspects of Payment Card Systems and Antitrust Policy toward Joint Ventures," Antitrust Law Journal, 63(3): 861-901.

[6] Farrell, J. (2006) "Efficiency and Competition between Payment Instruments", Review of Network Economics, 5(1): 26-44.

[7] Frankel, A. S. (1998) "Monopoly and Competition in the Supply and Exchange of Money," Antitrust Law Journal, 66(2): 313-361.

[8] Guthrie, G. and J. Wright (2007) "Competing Payment Schemes," Journal of Industrial Economics, LV: 37-67.

[9] Lal, R., and C. Matutes (1994) "Retail Pricing and Advertising Strategies," Journal of Business, 67: 345-370.

[10] Mankiw, G., and M. Whinston (1986) "Free Entry and Social Inefficiency," Rand Journal of Economics, 17(1): 48-58.

[11] Prékopa, A. (1973) "On Logarithmic Concave Measures and Functions," Acta Scientiarum Mathematicarum, 34: 339-343.

[12] Rochet, J.-C. (2003) "The Theory of Interchange Fees: A Synthesis of Recent Contributions," Review of Network Economics, 2(2): 97-124. 
[13] Rochet, J.-C., and J. Tirole (2002) "Cooperation among Competitors: Some Economics of Payment Card Associations," Rand Journal of Economics, 33(4): 549-570.

[14] — (2003) "Platform Competition in Two-Sided Markets," Journal of the European Economic Association, 1(4): 990-1029.

[15] Schmalensee, R. (2002) "Payment Systems and Interchange Fees," Journal of Industrial Economics, 50(2): 103-122.

[16] — (2003) "Interchange Fees: A Review of the Literature," in The Payment Card Economics Review, Vol. 1, Cambridge: payingwithplastic.org/National Economic Research Associates, 2003: 25-44.

[17] Vickers, J. (2005) "Public Policy and the Invisible Price: Competition Law, Regulation and the Interchange Fee", Proceedings of a conference on "Interchange Fees in Credit and Debit Card Industries" (Federal Reserve Bank of Kansas-City, Santa Fe, New Mexico, May 4-6, 2005) 231-247.

[18] Weyl, E. Glen (2008) "Pass-through, Double Marginalization and Two-Sided Markets," http://www.princeton.edu/ eweyl/Pass_through_4_08.pdf

[19] Wright, J. (2003a) "Optimal Card Payment Systems," European Economic Review, 47: $587-612$.

[20] — (2003b) "Pricing in Debit and Credit Card Schemes," Economics Letters, 80: 305-309.

[21] — (2004) "The Determinants of Optimal Interchange Fees in Payment Systems," Journal of Industrial Economics, 52(1): 1-26. 


\section{Appendix 1: Retailers' card acceptance in the Hotelling- Lerner-Salop model}

This appendix shows that, when retailers compete as in the Hotelling-Lerner-Salop model, and consumers only learn retailers' card acceptance policies with probability $\alpha \leq 1$, retailers accept cards at equilibrium if and only if $p_{S} \leq b_{S}+\alpha v_{B}\left(p_{B}\right)$. In the special case where $\alpha=1$, this establishes the last part of Proposition 1 (the first and second parts were proven in the text). We prove this result for arbitrary $\alpha$.

We also provide an explicit model of competition in the (card good) retail sector, using the Lerner-Salop model of product differentiation: Retailers and consumers are located uniformly on a circle of length normalized to one. The timing is as follows:

1. First, each consumer learns his preference across brands of the card good offered by the retailers, as well as the prices chosen by the retailers. Furthermore, he learns all stores' card acceptance policies with probability $\alpha$, and does not learn any with probability $1-$ $\alpha .^{29}$ The consumer then chooses which store to patronize. The optimal choice minimizes the sum of three terms: the retail price $p_{R}^{j}$, the transportation cost $t \Delta^{j}$ incurred from going to the store (where $\Delta^{j}$ is the distance to the store and $t>0$ is a given parameter), and the expected transaction cost associated with the payment mode (this term is detailed below).

2. Second, after choosing a store, the consumer learns his convenience benefit of using a card rather than cash in the particular instance, and chooses the payment mode among the ones accepted by the retailer. The relative cost $\widetilde{b}_{B}$ of the alternative payment mode (cash) is random, and drawn from another continuous distribution with cumulative distribution function $H$ :

$$
H\left(b_{B}\right)=\operatorname{Pr}\left(\widetilde{b}_{B} \leq b_{B}\right) .
$$

As we noted, this convenience benefit $\widetilde{b}_{B}$ is observed by the consumer only once he is in the store. The net benefit of paying by card is thus equal to the difference $\widetilde{b}_{B}-p_{B}$. A card payment is optimal for the consumer whenever this net benefit is positive. The

\footnotetext{
${ }^{29}$ It may seem strange that when $\alpha<1$ some consumers know the prices, but not the card acceptance decisions. Note however that a) they do not need to know all retailers prices (as in Lal-Matutes 1994, it suffices that they know at least one price for the reasoning to apply), and b) whether they know some price or not, card acceptance helps attract consumers. In this latter case, the acceptance threshold is a non linear function of $\alpha$.
} 
proportion of card payments is denoted $D_{B}\left(p_{B}\right)$ :

$$
D_{B}\left(p_{B}\right)=\operatorname{Pr}\left(\widetilde{b}_{B}>p_{B}\right)=1-H\left(p_{B}\right) .
$$

Retailers $j=1, \cdots, R$ compete in two stages: $:^{30}$

1. First, they simultaneously decide whether to accept the card. We denote the decision of retailer $j$ by a variable $x^{j}$ equal to 1 if retailer $j$ accepts the card, and 0 if he does not.

2. Second, they simultaneously set their retail prices: $p^{j}$ is chosen by retailer $j$ so as to maximize his profit:

$$
\pi^{j}=\left[p^{j}-\gamma-b_{S}-x^{j}\left(p_{S}-b_{S}\right) D_{B}\left(p_{B}\right)\right] y^{j}
$$

where $\gamma$ is the cost of producing the card good, and $b_{S}$ is the cost of the alternative payment mode for the seller (assumed constant across sellers). Thus $\left(p_{S}-b_{S}\right) D_{B}\left(p_{B}\right)$ represents the expected net cost of card payments for the seller (incurred only when $\left.x^{j}=1\right)$. Finally, $y^{j}$ represents the market share of retailer $j$.

Retailer $j$ 's market share is a function of the retail prices set by retailer $j$ and his neighbors $j-1$ and $j+1$, as well as the card acceptance decisions $x^{j}, x^{j-1}$ and $x^{j+1}$ :

$$
y^{j}=\frac{1}{R}+\frac{1}{2 t}\left[p^{j-1}+p^{j+1}-2 p^{j}-\alpha\left(x^{j-1}+x^{j+1}-2 x^{j}\right) s_{B}\left(p_{B}\right)\right]
$$

where

$$
s_{B}\left(p_{B}\right) \equiv \int_{p_{B}}^{\infty}\left(b_{B}-p_{B}\right) d H\left(b_{B}\right)
$$

denotes the expected surplus that a buyer derives from the option of paying by card. Our next proposition relates the retailers' acceptance decision to prices $p_{B}$ and $p_{S}$ and to the internalization parameter $\alpha .^{31}$

Proposition 12. The retail sector equilibrium is unique and symmetric.

- retailers (all) accept the card if and only if:

$$
p_{S} \leq b_{S}+\alpha v_{B}\left(p_{B}\right)
$$

(otherwise none accepts the card). If this condition is satisfied, then:

\footnotetext{
${ }^{30}$ The timing here is irrelevant: the equilibrium would be the same if the first and second stages were simultaneous. This is because we assume that consumers' transactional benefits are drawn ex post.

${ }^{31}$ Proposition 12 can easily be extended to the case where two card networks offer identical cards and set identical IFs.
} 
- retailers pass through card transaction costs (or benefits) into the retail price:

$$
p^{*}=\gamma+b_{S}+\frac{t}{R}-\left(b_{S}-p_{S}\right) D_{B}\left(p_{B}\right)
$$

(where $\gamma+b_{S}$ is the marginal cost of a cash transaction and $\frac{t}{R}$ the Hotelling markup), and the total profit of the retail sector is constant:

$$
\pi=\frac{t}{R}
$$

- consumers' total purchase cost is given by:

$$
\left[\gamma+E\left(\widetilde{b}_{B}\right)+b_{S}\right]+\frac{5 t}{4 R}-\phi\left(p_{B}\right)
$$

\section{Proof of Proposition 12}

Suppose, first, that all retailers accept the card. In this case, formulas (29) and (30) show that the profit of retailer $j$ is maximized when

$$
0=\frac{\partial \pi^{j}}{\partial p^{j}}=y^{j}-\left[p^{j}-\gamma-b_{S}-\left(p_{S}-b_{S}\right) D_{B}\left(p_{B}\right)\right] / t .
$$

The equilibrium market shares are all equal $\left(y^{j} \equiv \frac{1}{R}\right)$, and so are retail prices:

$$
p^{j} \equiv p^{*}=\left[\gamma+b_{S}+\frac{t}{R}\right]-\left(b_{S}-p_{S}\right) D_{B}\left(p_{B}\right)
$$

which establishes formula (32). Consumer total purchase cost is then equal to the sum of the retail price $p^{*}$, the average transportation cost $\frac{t}{4 R}$ and the expected transaction cost for the cardholder $E\left(\widetilde{b}_{B}\right)+\int_{p_{B}}^{\infty}\left(p_{B}-b_{B}\right) d H\left(b_{B}\right)$. Formulas (34) and (33) are then immediate.

Suppose now that retailer $j$ considers rejecting the card. A new price equilibrium arises where all retailers except $j$ increase their price and market share, whereas retailer $j$ decreases his price and market share but also his cost (assuming $b_{S}<p_{S}$ ). It is easy to check that the net effect is to decrease retailer $j$ 's profit if and only if

$$
\phi_{\alpha} \equiv\left(b_{S}-p_{S}\right) D_{B}\left(p_{B}\right)+\alpha \int_{p_{B}}^{\infty}\left(b_{B}-p_{B}\right) d H\left(b_{B}\right) \geq 0 .
$$

We call $\phi_{\alpha}$ the weighted total user surplus. ${ }^{32}$ Intuitively, with a linear demand (stemming from the uniform distribution of consumers), retailer $j$ can lower his price by $\alpha \int_{p_{B}}^{\infty}\left(b_{B}-\right.$

\footnotetext{
${ }^{32}$ Note that when $\alpha=1, \phi_{\alpha}$ coincides with total user surplus: $\phi_{1}=\phi$.
} 
$\left.p_{B}\right) d H\left(b_{B}\right)$ and keep the same market share as when he accepts the card. The first term in the latter inequality is (minus) the cost saving associated with rejecting the card. The condition is thus equivalent to the assertion that accepting the card maximizes the perceived or weighted total user surplus, where only a fraction $\alpha$ of the buyer surplus from using the card is internalized. More formally, since $\phi_{\alpha}$ has the same sign as $\frac{\phi_{\alpha}}{D_{B}\left(p_{B}\right)}$ we have that:

$$
\phi_{\alpha} \geq 0 \Leftrightarrow \frac{\phi_{\alpha}}{D_{B}\left(p_{B}\right)}=b_{S}-p_{S}+\alpha v_{B}\left(p_{B}\right) \geq 0
$$

This condition ends the proof of formula (31) and, thus, of Proposition 12. The equilibrium is unique.

\section{Appendix 2: Proof of Proposition 3}

For convenience, we take $p_{B}$ (instead of $a$ ) as the variable of interest. By assumption, $p_{B}$ is increasing in $c_{I}=c_{B}-a$, which implies that $p_{B}$ is decreasing in $a$. We can thus reason on $p_{B}$, keeping in mind that an increase in the IF results in a decrease in $p_{B}$.

The total profit of the members of the payment card association (that is of the issuers, since acquirers make no profit in our model) is thus:

$$
\pi_{B}=m\left(p_{B}\right) D_{B}\left(p_{B}\right)
$$

We assume that, provided that merchants are kept on board, $\pi_{B}$ is decreasing in $p_{B}$ : issuers prefer higher IFs.

The interchange fee $a$ passes the tourist test if and only if

$$
a \leq a^{T} \equiv b_{S}-c_{S} \quad \Longleftrightarrow \quad p_{B} \geq p_{B}^{T} \equiv c-b_{S}+m\left(p_{B}^{T}\right)
$$

$p_{B}^{T}$ is uniquely defined since $m^{\prime}<1$. Similarly the socially optimal interchange fee is:

$$
a^{W}=c_{B}-p_{B}^{W}+m\left(p_{B}^{W}\right)
$$

where $p_{B}^{W}=c-b_{S}$. Thus

$$
a^{W}=b_{S}-c_{S}+m\left(p_{B}^{W}\right)>a^{T}
$$

Finally, total user surplus

$$
\phi\left(p_{B}\right)=\int_{p_{B}}^{\infty}\left[b_{B}+b_{S}-c-m\left(p_{B}\right)\right] d H\left(b_{B}\right)
$$


is maximized for a value $p_{B}^{T U S}$ that satisfies the first-order condition:

$$
\phi^{\prime}\left(p_{B}\right)=\left[p_{B}+b_{S}-c-m\right] D_{B}^{\prime}-m^{\prime} D_{B}=0 .
$$

Thus

$$
p_{B}^{T U S}=c-b_{S}+m+\frac{m^{\prime} D_{B}}{D_{B}^{\prime}}=p_{B}^{W}+\frac{\left(m D_{B}\right)^{\prime}}{D_{B}^{\prime}} .
$$

Since $\left(m D_{B}\right)^{\prime}<0$ and $D_{B}^{\prime}<0, p_{B}^{T U S}$ is higher than $p_{B}^{W}$. Finally, the corresponding interchange fee $a^{T U S}$ is given by:

$$
a^{T U S}=c_{B}-p_{B}^{T U S}+m\left(p_{B}^{T U S}\right)=b_{S}-c_{S}-\frac{m^{\prime} D_{B}}{D_{B}^{\prime}}\left(p_{B}^{T U S}\right)=a^{T}-\frac{m^{\prime} D_{B}}{D_{B}^{\prime}}\left(p_{B}^{T U S}\right) .
$$

Remark (acquirer margins): As in the case of constant margins, the analysis can be extended to allow for acquirer margins. The welfare optimal IF remains $a^{W}=b_{S}-c_{S}+$ $m_{B}\left(p_{B}\right)$. By contrast, the formula for the TUS optimum is altered. ${ }^{33}$

\section{Appendix 3: Retailers' acceptance decisions under par- tial multi-homing}

We extend the analysis of Appendix 1 to the case of two competing cards, with partial buyers' multi-homing.

For simplicity, this appendix takes as given the proportions of buyers who own the two cards. Specifically, let $\beta_{k}(k=1,2)$ denote the proportion of buyers who own only card $k$ (the single-homers) and $\beta_{12}$ denote the proportion of buyers who own both cards (the multi-homers). Like before, we assume for simplicity that all consumers have a card ${ }^{34}$ (i.e., $\beta_{1}+\beta_{2}+\beta_{12}=1$ ). The next proposition characterizes the equilibrium of the retail sector (both in terms of card acceptance and retail prices) as a function of payment card prices and parameters $\beta_{1}, \beta_{2}$ and $\beta_{12}$.

\footnotetext{
${ }^{33}$ Letting $m_{S}\left(p_{S}\right)=m_{S}\left(c_{S}+a\right)=m_{S}\left(c+m_{B}\left(p_{B}\right)-p_{B}\right)$ denote the acquirers' markup, then at the TUS optimum,

$$
p_{B}+b_{S}-\left(c+m_{B}+m_{S}\right)=\frac{D_{B}}{D_{B}^{\prime}}\left[m_{B}^{\prime}-m_{S}^{\prime}\left(1-m_{B}^{\prime}\right)\right] .
$$

${ }^{34}$ This is not inconsistent with our model, which assumes that issuers do not charge fixed fees to cardholders.
} 
Proposition 13. At the equilibrium of the retail sector:

- retailers accept both cards if and only if:

$$
\beta_{1} \phi\left(p_{B}^{1}\right)+\left(\beta_{2}+\beta_{12}\right) \phi\left(p_{B}^{2}\right) \geq \max \left[0,\left(\beta_{1}+\beta_{12}\right) \phi\left(p_{B}^{1}\right),\left(\beta_{2}+\beta_{12}\right) \phi\left(p_{B}^{2}\right)\right] .
$$

If this condition is satisfied then:

- retail prices ${ }^{35}$ are given by:

$$
p^{*}=\left[\gamma+b_{S}+\frac{t}{R}\right]-\beta_{1}\left(b_{S}-p_{S}^{1}\right) D_{B}\left(p_{B}^{1}\right)-\left(\beta_{2}+\beta_{12}\right)\left(b_{S}-p_{S}^{2}\right) D_{B}\left(p_{B}^{2}\right),
$$

- aggregate demand for the card good equals ${ }^{36} \beta_{1} D\left(u_{1}^{*}\right)+\left(\beta_{2}+\beta_{12}\right) D\left(u_{2}^{*}\right)$, where

$$
u_{k}^{*}=p^{*}+\frac{t}{4 R}+E\left(\widetilde{b}_{B}\right)-s_{B}\left(p_{B}^{k}\right), \quad k=1,2 .
$$

- consumer surplus equals $\beta_{1} S\left(u_{1}^{*}\right)+\left(\beta_{2}+\beta_{12}\right) S\left(u_{2}^{*}\right)$,

- finally, the total profit of the retail sector is

$$
\pi=\frac{t}{R}\left[\beta_{1} D\left(u_{1}^{*}\right)+\left(\beta_{2}+\beta_{12}\right) D\left(u_{2}^{*}\right)\right]
$$

\section{Proof of Proposition 13:}

It proceeds similarly to that of Proposition 12 in Appendix 1. In equilibrium, retailers accept the (set of) cards that maximize the expectation of total user surplus $\phi$ over all buyers. Accepting only card $k(k=1,2)$ allows a fraction $\left(\beta_{k}+\beta_{12}\right)$ of buyers to pay by card generating total user surplus $\phi\left(p_{B}^{k}\right)$. The right-hand side of condition (37) corresponds to the maximum of three outcomes: accepting no card, accepting card 1 alone, and accepting card 2 alone. The left-hand side of condition (37) corresponds to the expectation of weighted user surplus when the merchant accepts both cards. In this case multi-homers prefer to use card 2 (since $\left.p_{B}^{2} \leq p_{B}^{1}\right)$, which explains the fraction $\left(\beta_{2}+\beta_{12}\right)$ of buyers who use card 2. This establishes the first bullet point in Proposition 13. Retail prices (second bullet point) are given at equilibrium by the average unit cost faced by merchants (including the net cost of card payments) plus a constant margin $\frac{t}{R}$. The other bullet points are immediate.

\footnotetext{
${ }^{35}$ We assume that retailers find it too costly or are not allowed to charge different prices for transactions settled through different cards.

${ }^{36}$ For simplicity, we assume that the determinants of the choice of cards by consumers are independent from the parameters that determine the gross utility $\tilde{u}$ obtained by consumers when they consume the card good.
} 


\section{Appendix 4: Proof of Proposition 10}

Social welfare is given by:

$$
W\left(p_{B}, \widehat{b}_{S}\left(p_{B}\right)\right)=\int_{\widehat{b}_{S}}^{\infty} \int_{p_{B}}^{\infty}\left[b_{S}+b_{B}-c\right] d H\left(b_{B}\right) d G\left(b_{S}\right)
$$

where $\widehat{b}_{S}\left(p_{B}\right)=p_{S}-v_{B}\left(p_{B}\right)=c+m-p_{B}-v_{B}\left(p_{B}\right)$. Since we have assumed that issuers' margin $m$ is constant, social welfare is maximized for a value $p_{B}^{W}$ of buyers' price such that:

$$
\frac{\partial W}{\partial p_{B}}\left(p_{B}^{W}, \widehat{b}_{S}^{W}\right)=\frac{\partial W}{\partial \widehat{b}_{S}}\left(p_{S}^{W}, \widehat{b}_{S}^{W}\right)\left(1+v_{B}^{\prime}\left(p_{B}^{W}\right)\right)
$$

where $\widehat{b}_{S}^{W}=\widehat{b}_{S}\left(p_{B}^{W}\right)$.

Using formula (38) we see that

$$
\frac{\partial W}{\partial p_{B}}\left(p_{B}^{W}, \widehat{b}_{S}^{W}\right)=D_{B}^{\prime}\left(p_{B}^{W}\right) \int_{\hat{b}_{S}^{W}}^{\infty}\left(p_{B}^{W}+b_{S}-c\right) d G\left(b_{S}\right)
$$

Now by definition:

$$
v_{S}\left(\widehat{b}_{S}^{W}\right) D_{S}\left(\widehat{b}_{S}^{W}\right)=\int_{\hat{b}_{S}^{W}}^{\infty}\left(b_{S}-\widehat{b}_{S}^{W}\right) d G\left(b_{S}\right)=\int_{b_{S}^{W}}^{\infty}\left(b_{S}-c-m+p_{B}^{W}+v_{B}\left(p_{B}^{W}\right)\right) d G\left(b_{S}\right) .
$$

Thus we can write:

$$
\frac{\partial W}{\partial p_{B}}\left(p_{B}^{W}, \widehat{b}_{S}^{W}\right)=D_{B}^{\prime}\left(p_{B}^{W}\right) D_{S}\left(\widehat{b}_{S}^{W}\right)\left[v_{S}\left(\widehat{b}_{S}^{W}\right)+m-v_{B}\left(p_{B}^{W}\right)\right] .
$$

Similarly

$$
\frac{\partial W}{\partial \widehat{b}_{S}}\left(p_{B}^{W}, \widehat{b}_{S}^{W}\right)=D_{S}^{\prime}\left(\widehat{b}_{S}^{W}\right) \cdot \int_{p_{B}^{W}}^{\infty}\left(\widehat{b}_{S}^{W}+b_{B}-c\right) d H\left(b_{B}\right)
$$

while

$$
v_{B}\left(p_{B}^{W}\right) D_{B}\left(p_{B}^{W}\right)=\int_{p_{B}^{W}}^{\infty}\left(b_{B}-p_{B}^{W}\right) d H\left(b_{B}\right)
$$

Thus:

$$
\frac{\partial W}{\partial \widehat{b}_{S}}\left(p_{B}^{W}, \widehat{b}_{S}^{W}\right)=D_{S}^{\prime}\left(\widehat{b}_{S}^{W}\right) D_{B}\left(p_{B}^{W}\right)\left[v_{B}\left(p_{B}^{W}\right)-v_{B}\left(p_{B}^{W}\right)+m\right] .
$$

Thus the first-order condition for welfare maximization can be rewritten as:

$$
\frac{D_{B}^{\prime}\left(p_{B}^{W}\right)}{D_{B}\left(p_{B}^{W}\right)}\left[v_{S}\left(\widehat{b}_{S}^{W}\right)+m-v_{B}\left(p_{B}^{W}\right)\right]=\frac{D_{S}^{\prime}\left(\widehat{b}_{S}^{W}\right)}{D_{S}\left(\widehat{b}_{S}^{W}\right)}\left[v_{B}\left(p_{B}^{W}\right)-v_{B}\left(p_{B}^{W}\right)+m\right]\left(1+v_{B}^{\prime}\left(p_{B}^{W}\right)\right) .
$$

This is equivalent to formula (23). 
Total User Surplus (TUS) is equal to:

$$
\phi\left(p_{B}, \widehat{b}_{S}\left(p_{B}\right)\right)=\int_{\widehat{b}_{S}\left(p_{B}\right)}^{\infty} \int_{p_{B}}^{\infty}\left[b_{B}+b_{S}-c-m\right] d H\left(b_{B}\right) d G\left(b_{S}\right) .
$$

Note that, by definition of $\widehat{b}_{S}\left(p_{B}\right)$ we have that:

$$
\forall p_{B}, \frac{\partial \phi}{\partial \widehat{b}_{S}}\left(p_{B}, \widehat{b}_{S}\left(p_{B}\right)\right)=0
$$

This is because

$$
\int_{p_{B}}^{\infty}\left[b_{B}+\widehat{b}_{S}\left(p_{B}\right)-c-m\right] d H\left(b_{B}\right) \equiv 0 .
$$

Thus TUS is maximum for $p_{B}^{T U S}$ such that

$$
\frac{\partial \phi}{\partial \widehat{b}_{S}}\left(p_{B}, \widehat{b}_{S}\left(p_{B}\right)\right)=0=\int_{\widehat{b}_{S}\left(p_{B}\right)}^{\infty}\left[p_{B}+b_{S}-c-m\right] d G\left(b_{S}\right) .
$$

Since $\widehat{b}_{S}\left(p_{B}\right)=p_{S}+v_{B}\left(p_{B}\right)$, this is equivalent to formula $(24)$.

\section{Appendix 5: Proof of Proposition 11}

Given our assumption that issuers' margin is constant, their profit is maximized for a value $p_{B}^{m}$ of buyers' price that maximizes the volume of card transactions, given by:

$$
V\left(p_{B}\right)=D_{B}\left(p_{B}\right) D_{S}\left(\widehat{b}_{S}\left(p_{B}\right)\right)
$$

where $\widehat{b}_{S}\left(p_{B}\right)=c+m-p_{B}-v_{B}\left(p_{B}\right)$.

Now $p_{B}^{m}$ is given by the first-order condition:

$$
\frac{V^{\prime}}{V}\left(p_{B}^{m}\right)=\frac{D_{B}^{\prime}}{D_{B}}\left(p_{B}^{m}\right)-\frac{D_{S}^{\prime}}{D_{S}}\left(\widehat{b}_{S}^{m}\right)\left(1+v_{B}^{\prime}\left(p_{B}^{m}\right)\right)=0
$$

which gives (26).

When social welfare is quasi-concave with respect to the buyer price, the privately optimal IF (associated with buyer price $p_{B}^{m}$ and seller threshold $\widehat{b}_{S}^{m}=\widehat{b}_{S}\left(p_{B}^{m}\right)$ ) is excessively low whenever

$$
\Delta \equiv \frac{\partial W}{\partial p_{B}}\left(p_{B}^{m}, \widehat{b}_{S}^{m}\right)-\left[1+v_{B}^{\prime}\left(p_{B}^{m}\right)\right] \frac{\partial W}{\partial \widehat{b}_{S}}\left(p_{B}^{m}, \widehat{b}_{S}^{m}\right)<0 .
$$

Adapting the formulas obtained above, we see that

$$
\begin{aligned}
\Delta= & D_{B}^{\prime}\left(p_{B}^{m}\right) D_{S}\left(\widehat{b}_{S}^{m}\right)\left[v_{S}\left(\widehat{b}_{S}^{m}\right)+m-v_{B}\left(p_{B}^{m}\right)\right] \\
& -\left[1+v_{B}^{\prime}\left(p_{B}^{m}\right)\right] D_{S}^{\prime}\left(\widehat{b}_{S}^{m}\right) D_{B}\left(p_{B}^{m}\right)\left[v_{B}\left(p_{B}^{m}\right)-v_{B}\left(p_{B}^{m}\right)+m\right] .
\end{aligned}
$$


Applying condition (26) allows us to simplify this expression:

$$
\begin{aligned}
\Delta & =D_{B}^{\prime}\left(p_{B}^{m}\right) D_{S}\left(\widehat{b}_{S}^{m}\right)\left[v_{S}\left(\widehat{b}_{S}^{m}\right)+m-v_{B}\left(p_{B}^{m}\right)-v_{B}\left(p_{B}^{m}\right)+v_{B}\left(p_{B}^{m}\right)-m\right] \\
& =D_{B}^{\prime}\left(p_{B}^{m}\right) D_{S}\left(\widehat{b}_{S}^{m}\right)\left[v_{S}\left(\widehat{b}_{S}^{m}\right)-v_{B}\left(p_{B}^{m}\right)\right] .
\end{aligned}
$$

Thus $\Delta<0 \Leftrightarrow v_{S}\left(\widehat{b}_{S}^{m}\right)>v_{B}\left(p_{B}^{m}\right)$, and the proof of Proposition 11i) is complete.

To establish 11ii) it suffices to notice that $v_{S}\left(\widehat{b}_{S}^{m}\right)=E\left(b_{S} \mid \widehat{b}_{S}^{m}\right)-p_{S}^{m}+v_{B}\left(p_{B}^{m}\right)$.

Part iii) results from the comparison of formulas (23) and (26).

\section{Appendix 6: Elastic demand for the retail good}

This appendix extends Proposition 2 to the case where final demand is elastic. In a symmetric equilibrium where all retailers accept cards and charge the same retail price $p$, this demand is a decreasing function $D(\widehat{p})$ of the "hedonic" price $\widehat{p}$ that incorporates expected transaction costs, and is defined by:

$$
\widehat{p} \equiv p+E\left[\min \left(\widetilde{b}_{B}, p_{B}\right)\right] .
$$

Retailers' profit equals

$$
R P=\left[p-\gamma-\left(p_{S}-b_{S}\right) D_{B}\left(p_{B}\right)\right] D(\widehat{p})
$$

or:

$$
R P=\left(\widehat{p}-\gamma-E\left(b_{B}\right)-b_{S}-\phi\left(p_{B}\right)\right) D(\widehat{p}),
$$

where

$$
\phi\left(p_{B}\right)=\int_{p_{B}}^{\infty}\left(b_{B}+b_{S}-c-m\right) d H\left(B_{B}\right) .
$$

Given formula (40), the equilibrium hedonic price is a function of $\phi\left(p_{B}\right)$ denoted $\widehat{p}(\phi)$, that we can reasonably assume to be decreasing. Similarly we can write the equilibrium value of retailers' profit and consumer surplus as $R P(\phi)$ and $C S(\phi)$. It is legitimate to assume that both $R P$ and $C S$ are increasing functions of $\phi$. Thus, like in the case of inelastic demand, the value of $p_{B}$ that maximizes consumer surplus is the one that maximizes $\phi$, that is $p_{B}^{T U S}=c-b_{S}+m$ (in the case where issuers' margin $m$ is constant). The second part of Proposition 2 (namely $2 i i$ )) can therefore be extended to elastic retail demand. The first part is more difficult to generalize. Indeed, social welfare equals:

$$
W\left(p_{B}\right)=C S\left(\phi\left(p_{B}\right)\right)+R P\left(\phi\left(p_{B}\right)\right)+m D_{B}\left(p_{B}\right) D(\widehat{p}(\phi)) .
$$


Thus

$$
W^{\prime}\left(p_{B}\right)=\phi^{\prime}\left(p_{B}\right)\left[C S^{\prime}(\phi)+R P^{\prime}(\phi)+m D_{B}\left(p_{B}\right) D^{\prime}(\widehat{p}) \widehat{p}^{\prime}(\phi)\right]+m D_{B}^{\prime}\left(p_{B}\right) D(\widehat{p}) .
$$

We have assumed that $\widehat{p}^{\prime}<0, C S^{\prime}>0$ and $R P^{\prime}>0$. Therefore the term in brackets is positive. If $W$ is quasi-concave in $p_{B}$, this implies that the socially optimal buyer price $p_{B}^{W}$ is lower than $p_{B}^{T}$, that maximizes $\phi$ :

$$
W^{\prime}\left(p_{B}^{T}\right)=m D_{B}^{\prime}\left(p_{B}^{T}\right) D(\widehat{p})<0=W^{\prime}\left(p_{B}^{W}\right)
$$

Therefore, we have established:

Proposition 2 bis. When retail demand is elastic (and issuers' margin constant):

i) The interchange fee $a^{W}$ that maximizes social welfare is higher than the tourist test threshold $a^{T}$,

ii) the interchange fee $a^{T U S}$ that maximizes total user surplus is equal to $a^{T}$.

Thus, the results of Proposition 2 are also valid when retail demand is elastic. 